\title{
AVALIAÇÃO DA MAGNITUDE DAS INTERFERÊNCIAS OCLUSAIS E SUA RELAÇÃO COM OS SINAIS CLÍNICOS DE TRAUMA OCLUSAL E SINAIS E SINTOMAS DE DESORDENS
}

TEMPOROMANDIBULARES.

\section{TATIANY DE MENDONÇA NETO}

\author{
Dissertação apresentada à Faculdade de Odontologia de \\ Bauru, da Universidade de São Paulo, como parte dos \\ requisitos para obtenção do título de mestre em Reabilitação \\ Oral.
}

Edição Revisada 


\title{
AVALIAÇÃO DA MAGNITUDE DAS INTERFERÊNCIAS OCLUSAIS E SUA RELAÇÃO COM OS SINAIS CLÍNICOS DE TRAUMA OCLUSAL E SINAIS E SINTOMAS DE DESORDENS
}

TEMPOROMANDIBULARES.

\section{TATIANY DE MENDONÇA NETO}

\author{
Dissertação apresentada à Faculdade de Odontologia de \\ Bauru, da Universidade de São Paulo, como parte dos \\ requisitos para obtenção do título de mestre em Reabilitação \\ Oral.
}

Edição Revisada

Orientador: Prof. Dr. Carlos dos Reis Pereira de Araujo 


\begin{tabular}{|c|c|}
\hline & Mendonça Neto, Tatiany \\
\hline \multirow[t]{4}{*}{ M523a } & $\begin{array}{l}\text { Avaliação da magnitude das interferências oclusais e sua relação com os } \\
\text { sinais clínicos de trauma oclusal e sinais e sintomas de desordens } \\
\text { temporomandibulares. } \\
\text { Tatiany de Mendonça Neto - Bauru, } 2003 \text {. }\end{array}$ \\
\hline & 94p.: il.; $30 \mathrm{~cm}$. \\
\hline & Dissertação. (Mestrado) - Faculdade de Odontologia de Bauru. USP. \\
\hline & Orientador: Prof. Dr. Carlos dos Reis Pereira de Araujo \\
\hline
\end{tabular}

Autorizo, exclusivamente para fins acadêmicos e científicos, a reprodução
total ou parcial desta dissertação, por processos fotocopiadores e/ou meios
eletrônicos.
Assinatura do autor:
Data:

Projeto aprovado pelo comitê de ética em pesquisa da Faculdade de Odontologia de Bauru - USP.

Protocolo de pesquisa $n^{0}$ 079/ 2002. 


\section{Tatiany de Mendonça Neto}

06 de junho de 1971

Inhumas - Go

$1991-1995$

$1997-1998$

$2001-2003$

Associações
Nascimento

Curso de graduação em Odontologia Faculdade de Odontologia - Universidade Federal de Goiás - FO - UFG.

Curso de Especialização em Prótese Dentária PROFIS, Bauru, SP.

Curso de Pós-graduação em Reabilitação Oral, ao nível de Mestrado, na Faculdade de Odontologia de Bauru - Universidade de São Paulo- FOB-USP. ABO - Associação Brasileira de Odontologia Secção de Goiás. 
Dedico este trabalho aos meus pais Joaquim e Osvaldina, pelo amor infinito e pelos sacrifícios realizados para nossa formação.

Vocês são a força quando eu estou fraca,

São minha voz quando eu não posso falar,

São meus olhos quando eu não posso ver.

Vocês são o melhor que há em mim,

Me levantam quando e u não posso alcançar.

Me dão fé porque acreditam em mim.

Eu sou tudo o que sou porque vocês me amam.

Vocês me dão asas e me fazem voar,

Seguram minha mão para que eu consiga tocar o céu.

Perco a minha fé, vocês a trazem de volta,

Vocês dizem que nenhuma estrela está fora de alcance,

Com vocês ao meu lado eu me sinto maior,

Eu fui abençoada, porque sou amada por vocês. 
Agradecimentos 


\section{A Deus}

Senhor,

No silêncio deste dia,

venho pedir-te a Paz, a Sabedoria, a Força.

Quero olhar o mundo com olhos cheios de Amor.

Ser paciente, compreensivo, manso e prudente,

ver além das aparências teus filhos

como Tu mesmo os vês, e assim...

Năo ver, senåo o bem em cada um.

Cerra meus ouvidos a toda calúnia,

Guarda minha lingua de toda maldade.

Que só de bênçăos se encha meu espirito.

Que eu seja tão bondosa e alegre,

que todos quantos se achegarem a mim

sintam Tua presença

Reveste-me de Tua beleza, Senhor

e que no decurso desta vida,

eu Te revele a todos. 
Aos meus irmãos Patrícia, Júnior, Ricardo, Elias, Elisa e Marcus

Pelo companheirismo, incentivo, apoio e preocupação com meu bemestar, sempre demonstrados pelo desejo de seguirmos juntos nossos sonhos.

"A Amizade é a união de dois espíritos afins criando entre eles um laço de ternura e de afeto, onde, cada um moverá montanhas pelo outro sem que se sinta o peso da terra".

\section{Ao William}

Por todas as vezes que você está ao meu lado,

por toda a verdade que você me faz ver,

por toda a alegria que você traz para a minha vida,

por tudo de errado que você torna correto,

por todo sonho que você torna realidade,

por todo amor que encontro em você,

serei eternamente agradecida. 
A minha família

Pelo apoio e incentivo demonstrados em todos os momentos da minha vida, principalmente pelos cuidados dispensados aos meus pais, na minha ausência.

\section{A Dra Fernanda e Dra Elaine}

Pelo carinho e amizade que sempre dispensaram nos ensinamentos dos primeiros passos da odontologia, e por me ensinarem que a felicidade ocorre na medida que fazemos os outros felizes.

Ao amigos Bruno, Juliana, Gildo, Jaci, Lawrence, Karina e Mauro

Pela amizade e carinho que transformaram esta batalha em inúmeros e inesquecíveis momentos agradáveis.

“Amigos são para sempre, mesmo que o sempre não exista”.

\section{A Professora Elaine}

Pela amizade e carinho demonstrados na difícil tarefa de ensinar os caminhos da língua inglesa. 


\section{Ao Professor Dr. Carlos}

Por ter me orientado com paciência e respeito, sempre solicito em resolver minhas dúvidas, demonstrando humanidade e carinho.

Ao Professor Dr. Acácio e Dra Tânia

Pela maneira com que me receberam e pelos ensinamentos da odontologia e da arte de viver entre amigos.

"Existem pessoas em nossas vidas que nos deixam felizes pelo simples fato de terem cruzado o nosso caminho".

\section{Ao Professor Dr. Pegoraro e Dra Leila}

Pela atenção, carinho e preocupação que foram dispensados nos momentos difíceis da minha vida. Obrigado pela orientação, transmitindo seus conhecimentos de maneira incansável e com muito respeito.

"A gente não faz amigos, reconhece-os".

\section{Ao Professor Gérson Bonfante}

Pelo carinho e atenção dispensados na orientação dos meus trabalhos, sempre me incentivando a fazer o melhor. 


\section{Ao Professor Paulo Conti}

Obrigado pela maneira atenciosa com que sempre respondeu as minhas dúvidas, e por estar sempre pronto a ajudar e ensinar.

Aos meus colegas de mestrado

Jefferson, Luciana, Mauro, Mariana, Luis Gustavo, Leilha, Paulo, Osvaldo, Rafael, Renato e Stela.

Pela valiosa ajuda nos momentos difíceis e pelos conhecimentos, transmitidos sem interesse, mas responsáveis pelo meu crescimento profissional.

"A amizade é um sentimento mais nobre que o amor, pois permite que o objeto dela se divida em outros afetos, enquanto o amor tem intrínseco o ciúme, que não admite a rivalidade”.

Aos meus colegas de doutorado

Carlos, Juliano, Nélson, Vinícius, Stefânia, Rudis e Anuar

Pela maneira atenciosa com que me receberam e por terem dividido comigo seus conhecimentos. 


\section{A Faculdade de Odontologia de Bauru}

Sob a tutela dos seus mestres pude aprimorar meus conhecimentos, com sábias orientações e exemplos de conduta profissional.

\section{Aos Professores do Departamento de Prótese da FOB - USP}

Por se preocuparem com nossa formação, orientando e transmitindo seus conhecimentos e experiências, com incentivo e apoio constantes.

Aos funcionários da FOB

Pela ajuda e o carinho que sempre demonstraram na execução dos meus trabalhos, em especial a Edna, Débora, Claudia, Reivanildo, Marcelo, Walquíria, Edlaine, Ivânia, Leuci, Cleusa, Ana, Aurélio e Geani que sempre demonstraram dedicação, paciência e amizade. Sem vocês seria impossível a realização deste trabalho.

"Aprendi que os amigos sempre ficam com você até o fim".

Aos funcionários da Biblioteca

Pelo carinho e amizade com que sempre me atenderam. 
Ao Professor Lauris e a professora Eloísa

Pelo cuidado e dedicação com que me ajudaram na estatística e correção ortográfica e gramatical dessa dissertação.

\section{A CAPES}

Pelo apoio financeiro, que proporcionou a realização deste trabalho. 


\section{SUMÁRIO}

Lista de figuras.............................................................. XV

Lista de tabelas....................................................................... XV

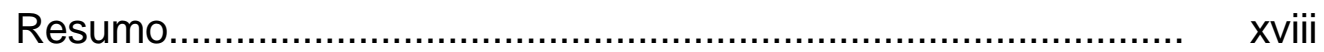

1 Introdução....................................................................... 1

2 Revisão da literatura............................................................. 5

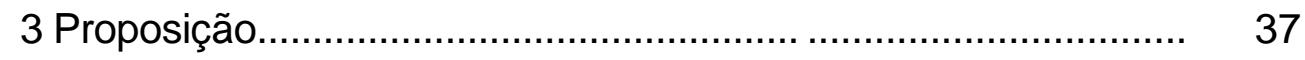

4 Material e Métodos.................................................................... 39

4.1 Amostra.................................................................... 40

4.2 Material........................................................................... 40

4.3 Exame Clínico..................................................................... 41

4.4 Análise estatística.............................................................. 46

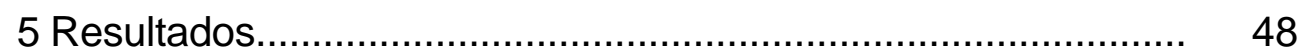

6 Discussão.................................................................... 58

7 Conclusão...................................................................... 73

Referências Bibliográficas........................................................ 75

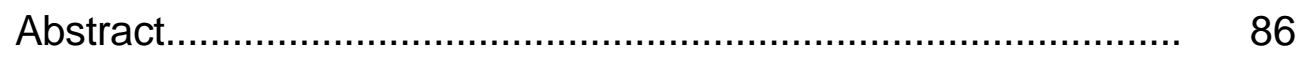

Anexos 
Listas 


\section{Lista de Figuras}

Figura 1: proteção dos dentes com vaselina para confecção do JIG

Figura 2: proteção dos dentes com papel alumínio para confecção do JIG.

Figura 3: resina acrílica na fase borrachóide para modelação para confecção do JIG

Figura 4: contato único no JIG

Figura 5: contato único no JIG para impedir qualquer contato dentário

Figura 6: contato interferente distante aproximadamente $1 \mathrm{~mm}$ do seu antagonista

Figura 7: registro da borda incisal do incisivo superior, na face vestibular do incisivo inferior, na posição de MIH

Figura 8: registro da borda incisal do incisivo superior, na face vestibular do incisivo inferior, na posição de RC

Figura 9: registro da magnitude da interferência oclusal

Figura 10: registro da magnitude da interferência oclusal 
Lista de Tabelas

Tabela 1: Comparação da magnitude da interferência oclusal $(\mathrm{mm})$ com sinais e sintomas de DTM e sinais clínicos de trauma oclusal

Tabela 2: Associação entre sexo e dor muscular, dor articular e ruído articular

Tabela 3: Associação entre evidências de interferência oclusal e dor muscular

Tabela 4: Associação entre evidências de interferência oclusal e dor articular

Tabela 5: Associação entre evidências de interferência oclusal e ruídos articulares

Tabela 6: Associação entre a magnitude da interferência oclusal e dor muscular

Tabela 7: Associação entre a magnitude da interferência oclusal e dor articular

Tabela 8: Associação entre a magnitude da interferência oclusal e ruído articular

Tabela 9: Associação entre a magnitude da interferência oclusal e evidências de interferência oclusal

Tabela 10: Associação entre a magnitude da interferência oclusal e facetas

Tabela 11: Associação entre a magnitude da interferência oclusal e mobilidade dentária

Tabela 12: Associação entre a magnitude da interferência oclusal e recessão gengival

Tabela 13: Associação entre a magnitude da interferência oclusal e abfração

Tabela 14: Associação entre a magnitude da interferência oclusal e dor dentária localizada

Tabela 15: Dados individuais referentes àmagni tude da interferência oclusal, idade, sexo, dor muscular, dor articular, presença de ruídos articulares, evidências de interferência oclusal, facetas, mobilidade dentária, recessão gengival, abfração e dor dentária localizada 
Resumo

xvii 


\section{RESUMO}

Apesar dos conhecimentos atuais mostrarem que a oclusão desempenha um papel relativamente pequeno na etiologia multifatorial das DTMs, publicações recentes demonstraram que algumas alterações oclusais e/ou esqueléticas aumentam o risco do indivíduo apresentar DTM. Dentre estas alterações está a diferença entre RC e MIH no sentido horizontal maior que $4 \mathrm{~mm}$. No entanto, ainda não se sabe qual o papel de uma interferência desta magnitude, no sentido vertical, como fator contribuinte para as DTMs. Este estudo verificou a relação de causa e efeito das interferências oclusais no sentido vertical avaliando a relação entre a magnitude da interferência oclusal com a presença de sinais sintomas de trauma oclusal e sinais e sintomas de DTM. Foram avaliados 43 pacientes, independente do gênero e idade, que não poderiam ser desdentados totais, não poderiam apresentar ausência de 5 ou mais unidades oclusais posteriores não substituídas e não poderiam estar em tratamento ortodôntico. O registro da magnitude da interferência oclusal foi feito na região anterior, através da borda incisal do incisivo superior, na face vestibular do incisivo inferior, nas posições de MIH e contato interferente em RC. A diferença em milímetros desta posição determinou a magnitude da interferência oclusal. Os resultados mostraram que as evidências de interferência oclusal estão presentes nos pacientes com e sem sinais e sintomas de DTM e sinais clínicos de trauma oclusal. Concluiu-se que não houve associação entre a magnitude das interferências oclusais e sinais clínicos de trauma oclusal e sinais e sintomas de Desordens Temporomandibulares.

Palavras-chave: interferência oclusal, desordens temporomandibulares, trauma oclusal, oclusão, posição de contato retruído. 


\section{INTRODUÇÃO}

Durante muito tempo, a oclusão foi conhecida como um dos principais fatores na etiologia multifatorial das disfunções temporomandibulares (DTMs). Dentre os fatores oclusais de risco, um dos principais é a presença de interferência oclusal $(\mathrm{IO})$, que pode ser definida como uma relação de contato oclusal que interfere de alguma forma com a função ou parafunção do sistema estomatognático ${ }^{14}$.

Do ponto de vista clínico, as interferências oclusais podem ser denominadas como traumas oclusais, os quais podem ser primários ou secundários. 0 trauma oclusal primário refere-se æ̀̀ interferências oclusais que atuam sobre os dentes com suporte periodontal sadio. Já trauma oclusal secundário está relacionado com as interferências oclusais que atuam em dentes previamente comprometidos por doença periodontal inflamatória. Nesses casos, a presença das interferências oclusais altera a função podendo levar a modificações ósseas, dentárias e pulpares. As alterações mais percebidas são mobilidade dentária, recessão gengival, faceta de desgaste, abfração e dor dentária localizada.

Apesar dos conhecimentos recentes, estudos ${ }^{18,19,20,23,27,29,46,}$ 50, 66, 68 sugerem que os fatores oclusais têm um papel limitado na etiologia da sintomatologia dolorosa e disfunção da articulação temporomandibular (ATM),

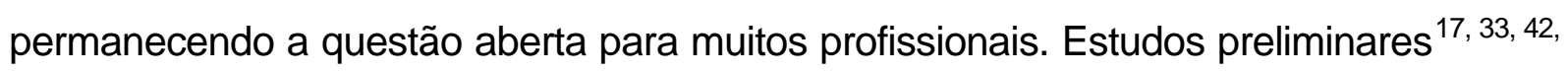


64, 69, 70 baseados em numerosas teorias sobre a etiologia e terapêutica das DTMs mostraram uma forte associação entre DTM e oclusão. Esses estudos, na maioria das vezes, ditaram as normas de tratamento, justificando terapias como placas oclusais, placas reposicionadoras, ajuste oclusal, procedimentos restauradores, tratamento ortodôntico e cirurgia ortognática. Por outro lado, muitas intervenções odontológicas, incluindo o tratamento ortodôntico de rotina, têm sido apontadas como causa das DTM.

Apesar dos conhecimentos atuais ${ }^{40,41,65,67,75}$ mostrarem que a oclusão desempenha um papel relativamente pequeno na origem multifatorial das DTMs, a influência da mesma continua sendo superestimada pelos clínicos e especialistas dessa área. Esta divergência de opinião tem um grande impacto na qualidade do diagnóstico e plano de tratamento, tanto das condições agudas quanto crônicas das DTMs. Um exemplo característico dessa divergência é a importância que se dá à pequena diferença que se forma entre a posição relação cêntrica $(R C)$ e a posição de máxima intercuspidação habitual $(\mathrm{MIH})$, quando estão presentes contatos prematuros ou interferências oclusais. Alguns autores ${ }^{09,27}$ acreditam que uma pequena diferença entre essas posições pode desencadear DTMs, enquanto outros ${ }^{46}, 58$ acreditam ser a mesma facilmente tolerada e absorvida de maneira fisiológica pelo sistema estomatognático. Portanto, a escolha entre um tratamento conservador e um tratamento irreversível dependerá dos conhecimentos, filosofias e crenças adotadas pelo profissional. 
As grandes divergências entre filosofias e planos de tratamento para as interferências oclusais motivaram a realização de inúmeros estudos. Estes, embora divergentes a respeito da relação entre interferências oclusais e DTM, são bem fundamentados cientificamente. Alguns estudos ${ }^{19,23,25,35,41,66}$ afirmam que grande parte da população apresenta interferências oclusais e não apresentam sinais e sintomas de DTM. Outros ${ }^{34,40,50}$, afirmam que pacientes com uma oclusão "perfeita" apresentam sinais e sintomas de DTM, havendo ainda outros ${ }^{23,24}$ que observaram a recidiva de sinais e sintomas de DTM em pacientes submetidos àcorreção oclusal.

$$
\text { Publicações recentes } 57,58,68 \text { demonstraram que algumas }
$$
alterações oclusais e/ou esqueléticas aumentam o risco de o indivíduo apresentar DTM. Dentre essas alterações está a diferença entre RC e MIH no sentido horizontal maior que $4 \mathrm{~mm}$. No entanto, não se sabe ainda qual o papel de uma interferência dessa magnitude, no sentido vertical, como fator contribuinte para as DTMs. Estudos preliminares $^{06,25,56}$ não conseguiram esclarecer se a magnitude das interferências oclusais atua de maneira diferente na etiologia das DTMs. Para resolver essa dúvida e determinar a relação de causa e efeito das interferências oclusais no sentido vertical, este trabalho avaliou a relação entre a magnitude da interferência oclusal com a presença de sinais clínicos de trauma oclusal e sinais e sintomas de DTM. 


\section{REVISÃO DA LITERATURA}

O papel deletério das interferências oclusais no sistema mastigatório e na articulação temporomandibular tem sido objetivo de numerosos trabalhos realizados em animais e humanos.

Os efeitos do trauma oclusal causado por interferências oclusais foram primeiramente estudados por GOTTLIEB; ORBAN ${ }^{28}$ em 1931. Os autores instalaram, experimentalmente, restaurações altas em dentes de 33 cães jovens e velhos os quais foram posteriormente sacrificados em períodos diferentes, que variaram de 12 horas a 13 meses. Após a análise histológica das mandíbulas, os autores observaram reabsorção do osso alveolar ao redor de dentes com restaurações altas já nas primeiras 24 horas. A rapidez da reabsorção óssea pareceu ser dependente da idade do animal, sendo mais rápida nos jovens que nos velhos. Nos períodos próximos aos 13 meses, os dentes movimentaram-se para uma nova posição com um tecido ósseo normal. A partir desses resultados, concluíram que os efeitos locais do trauma oclusal são transitórios em indivíduos saudáveis, embora não tenham quantificado a contribuição do trauma oclusal para os tecidos pulpares ou para a progressão da doença periodontal.

Em 1935, $\mathrm{BOX}^{07}$ avaliou o papel do trauma oclusal na progressão da doença periodontal, através da instalação de restaurações altas em incisivos inferiores de carneiros, que foram sacrificados após 104 dias. O autor utilizou métodos clínicos e histológicos para avaliar as amostras e observou aumento 
da mobilidade e profundidade de bolsa dos dentes experimentais, sugerindo 0 aumento da progressão da doença periodontal pela presença de trauma oclusal. Embora os dados tenham sido extremamente limitados, BOX precipitou-se ao afirmar que o trauma oclusal é um importante co-fator na progressão da doença periodontal.

WENTZ; JARABAK; ORBAN ${ }^{74}$, em 1958, avaliaram o efeito de forças laterais nos tecidos periodontais de segundos pré-molares superiores direitos em 6 macacos. Foram utilizadas restaurações altas combinadas com arco lingual para induzir forças laterais por um período que variava de dois dias a seis meses. Embora os resultados mostrassem a presença de reabsorção óssea e inflamação no tecido periodontal, nas amostras iniciais, as amostras de 3 a 6 meses revelaram que as alterações inflamatórias desapareceram em função da adaptação funcional do ligamento periodontal. Nesse estudo, os autores não tiveram a preocupação de controlar o processo inflamatório periodontal, uma variável importante para se saber qual o papel do trauma oclusal na doença periodontal. A análise dos resultados mostrou que os dados não eram suficientes para afirmar que o trauma oclusal pode acelerar a doença periodontal.

A presença de interferências oclusais no lado de trabalho e de não-trabalho tem um papel adverso no movimento da mandíbula. GRAF; ZANDER $^{29}$, em 1963, usaram um sistema telemétrico para medir o número de vezes que uma interferência experimental, no lado de não-trabalho, se tocava durante a função. Concluíram que houve um aumento no número de contatos da interferência 
experimental no lado de não-trabalho durante a mastigação, mas não observaram presença de dor ou desconforto na região mandibular, ou alterações no movimento mastigatório.

SHAERER; STALLARD; ZANDER ${ }^{66}$, em 1967, avaliaram 4 indivíduos com a finalidade de analisar a atividade eletromiográfica dos músculos masseter e temporal anterior e posterior, quando interferências oclusais experimentais estavam presentes no lado de não-trabalho, durante a mastigação. Os resultados mostraram que houve um aumento do número de contatos dentários no lado de não-trabalho. Embora $40 \%$ desses contatos tenham resultado em uma inibição da atividade eletromiográfica, não foi possível demonstrar o efeito deletério da interferência oclusal nos músculos durante o fechamento da mandíbula. A partir dos dados obtidos, concluiu-se que não foram observadas: (1) mudanças no padrão de mastigação, (2) aumento no número de ciclos de mastigação, (3) sintomas de DTM.

DE BOEVER ${ }^{18}$, em 1969, investigou se a presença de interferências oclusais experimentais no lado de não-trabalho poderia causar mudanças no padrão da atividade eletromiográfica do músculo temporal anterior durante a mastigação. Foram instaladas inlays de ouro em primeiros pré-molares de 4 estudantes com oclusão normal, com a finalidade de produzir interferências oclusais no lado de não-trabalho. O registro da atividade eletromiográfica do músculo temporal anterior foi realizado nos seguintes períodos: (1) antes da instalação das interferências oclusais (1 mês e imediatamente antes); (2) após a 
instalação das interferências oclusais (imediatamente, 1 dia, 3 e 8 dias após) e (3) após a remoção das interferências oclusais (imediatamente e após 10 dias). Os resultados não mostraram nenhuma alteração no padrão de atividade eletromiográfica do músculo temporal anterior bem como nenhuma alteração clínica nos dentes que receberam as interferências oclusais.

RUBEN; MAFLA 64 , em 1971, utilizaram 6 macacos para avaliar histologicamente os efeitos das interferências oclusais nas ATMs. Os macacos foram divididos em dois grupos. O grupo experimental era constituído de 4 macacos que tiveram a dimensão vertical de oclusão aumentada em $4 \mathrm{~mm}$, simulado por placas com contatos prematuros na área de primeiro molar. O grupo controle com 2 macacos, usou placas planas. As placas foram colocados por períodos de 15 a 55 dias antes de os macacos serem sacrificados e suas articulações submetidas a análise histológica. Os resultados mostraram destruição óssea evidente nos côndilos, na cavidade glenóide e no pescoço do côndilo, em ambas as amostras. Nas amostras de 55 dias, os côndilos foram deslocados mésio-inferiormente, com aplainamento na cabeça do côndilo e na eminência articular. Os dois tipos de placa causaram mudanças traumáticas nas articulações.

Em 1974, SVANBERG; LINDHE ${ }^{72}$ avaliaram o efeito de forças laterais experimentais em dentes de 13 cães, dos quais 9 apresentavam periodonto saudável e 4, apresentavam doença periodontal na região de quarto prémolar inferior. Através da utilização de um dispositivo no arco superior e uma barra no arco inferior simularam a presença de trauma oclusal. Os animais foram 
sacrificados após 7, 14, 30 e 180 dias. Os resultados mostraram que ambos os grupos apresentaram espessamento do ligamento periodontal e grande mobilidade dentária. No grupo com periodonto saudável, a mobilidade e espessamento foram diminuindo com o passar do tempo pela adaptação do periodonto. No grupo com doença periodontal, houve um aumento da vascularização, migração de leucócitos e atividade osteoclástica na região do periodonto. Os autores não correlacionaram o trauma oclusal com aumento da progressão da doença periodontal, acreditando ser a placa bacteriana o fator principal na progressão dessa doença.

Segundo um antigo conceito de DAWSON $^{17}$, em 1974, relação cêntrica é a posição mais retruída da mandíbula com relação ao maxilar, quando os côndilos estão em uma posição não forçada e mais posterior nas fossas glenóides, a partir das quais se podem fazer movimentos laterais em um determinado grau de separação mandibular (posição ligamentosa, posição terminal). Por acreditar na relação entre dor na musculatura mastigatória e interferência oclusal, DAWSON relatou que a presença de interferência pode envolver diversos músculos do sistema mastigatório, principalmente o músculo pterigóideo lateral, e causar espasmo e sensibilidade à palpação. O autor relatou que o diagnóstico diferencial entre DTM relacionada àpresença de interferência oclusal e dor auricular deveria ser realizado através da utilização de um dispositivo (Front Plateau). Se fosse constatado o desaparecimento da sintomatologia, o ajuste oclusal da interferência deveria ser feito como tratamento para remissão dos sintomas. 
GEERING $^{27}$, em 1974, avaliou 251 pacientes com o objetivo de investigar a relação das interferências oclusais com a ocorrência de desconforto na ATM e estruturas adjacentes. Embora verificando que a relação entre a presença de deslize de RC para $\mathrm{MIH}$ e sintomatologia dolorosa estava presente em 70 pacientes, não estabeleceu a relação entre a magnitude das interferências e a ocorrência de dor ou outros sintomas. Em uma segunda etapa do estudo, verificou a associação entre o deslize de RC para MIH e presença das interferências no lado de não-trabalho e encontrou uma relação entre esses fatores e os distúrbios do sistema mastigatório. O autor relatou que $40 \%$ dos pacientes que apresentaram interferências oclusais não associadas ao deslize não demonstraram sinais ou sintomas de DTM.

Em 1976, FUNAKOSHI; FUJITA; TAKEHANA ${ }^{26}$ estudaram a atividade eletromiográfica em repouso dos músculos masseter, temporal e digástrico de 3 pacientes, após instalação de interferências oclusais, simuladas aravés de restaurações com $300 \mu \mathrm{m}$ de altura em molares. Os registros foram realizados antes e durante os 7 dias de permanência da interferência e após 1 mês da retirada da mesma. Esses autores verificaram uma assimetria muscular funcional causada pela interferência, a qual diminuiu até voltar ao normal após a remoção da interferência. Não observaram nenhum sinal clínico na musculatura ou na articulação, no entanto verificaram dor no ligamento periodontal do dente com interferência.

POLSON; MEITNER; ZANDER ${ }^{54}$, em 1976, conduziram um estudo de interferência oclusal experimental em dentes de macacos com e sem 
doença periodontal. Eles encontraram que a inflamação dos tecidos periodontais induzida pela presença de placa foi o fator principal na progressão da doença periodontal e não o trauma oclusal.

Em 1979, SOLBERG; WOO; HOUSTON ${ }^{70}$, com a finalidade de estabelecer a prevalência de sinais e sintomas de DTM, avaliaram 739 pacientes adultos jovens. Os resultados desse trabalho mostraram que os deslizes de RC para $\mathrm{MIH}$, causados pela presença de interferências oclusais, podem estar associados aos sinais de DTM.

Em 1980, MOHLIN; INGERVALL; THILANDER ${ }^{50}$ estudaram a relação entre má oclusão, sintomas de DTM e interferências oclusais, e observaram que a etiologia das DTMs é multifatorial, não sendo possível predizer o risco desta em um indivíduo com má oclusão.

Em outro estudo, INGERVALL; MOHLIN; THILANDER ${ }^{33}$, em 1980, avaliaram 389 pacientes do sexo masculino, com idade média de 32 anos, com a finalidade de estabelecer a prevalência de sintomas de DTM e revelar a correlação entre os diferentes tipos de interferência oclusal. Os dados foram obtidos através de anamnese e exame clínico. Na anamnese, os indivíduos responderam a questionários sobre saúde geral e sobre os sintomas de DTM. O exame clínico incluiu a análise de: movimentos mandibulares; dor durante a função; ruídos articulares; sensibilidade muscular à palpação; sensibilidade articular à palpação; interferências oclusais. Os tipos de interferências oclusais foram: (a) contato dentário unilateral ou contato dentário anterior em RC; (b) contato em movimento lateral em 
$\mathrm{RC}$ e $\mathrm{MIH}$; (c) contato em que o desvio de $\mathrm{RC}$ para $\mathrm{MIH}$ foi maior que $2 \mathrm{~mm}$; (d) contato simples no lado de trabalho e de não-trabalho e contato unilateral em RC. Os resultados mostraram correlações positivas entre os sintomas subjetivos de DTM e a presença de interferências oclusais no lado de não trabalho, bem como contatos simples no lado de trabalho. A presença de contatos simples no lado de trabalho também foi relacionada com a presença de ruídos articulares causados por luxação ou fechamento da mandíbula. As interferências oclusais unilaterais em RC foram correlacionadas com sensibilidade muscular e ruídos articulares.

BAKKE; MOLLER ${ }^{05}$, em 1980, instalaram interferências oclusais de 50, 100, 150 e $200 \mu \mathrm{m}$ e mediram a atividade eletromiográfica dos músculos masseter e temporal bilateralmente durante a mastigação. Os resultados mostraram que contatos prematuros unilaterais causavam assimetria significante na atividade dos músculos masseter e temporal durante a mastigação. Eles relataram que a atividade eletromiográfica aumentou do lado da interferência oclusal e diminuiu do lado contrário.

Em 1981, BUDTZ-JORGENSEN ${ }^{09}$ realizou restaurações em dentes posteriores de 6 macacos para aumentar a dimensão vertical entre 3 e $4 \mathrm{~mm}$ e simular a presença de interferências oclusais unilaterais durante 4 semanas. Os dentes com interferência oclusal apresentaram aumento de mobilidade e facetas de desgaste nas restaurações durante o período experimental. A partir da análise dos dados, não puderam confirmar a hipótese de que alterações oclusais estão associadas com estresse emocional e podem resultar em bruxismo. Também não 
ficou claro se os macacos rangeram os dentes pela presença do estresse causado pelo experimento ou se pela presença da interferência. Como esse estudo não apresentou um grupo controle, não foi capaz de esclarecer esta dúvida.

RIISE; SHEIKHOLESLAM ${ }^{62}$, em 1982, realizaram restaurações experimentais de amálgama de $500 \mu \mathrm{m}$ de altura na superfície oclusal de primeiros molares superiores de 11 indivíduos sem sintomas de DTM. As interferências oclusais foram colocadas por sete dias e a atividade eletromiográfica registrada nos músculos masseter e temporal anterior em repouso nos seguintes períodos: (1) antes da instalação, (2) 1 hora, 48 horas e 1 semana após a instalação das mesmas e (3) 1 mês após a retirada das interferências. Os resultados mostraram que em 2 indivíduos, 1 hora após a instalação das interferências, ocorreu o aumento da atividade eletromiográfica no músculo temporal anterior de um lado. Também foi observado um aumento significante da atividade eletromiográfica no músculo temporal anterior direito em repouso após 48 horas e 1 semana da inserção da interferência. Dos 11 indivíduos, 8 desenvolveram sintomas disfuncionais após 12 horas de interferência e 7 reclamaram de dor, cansaço e fadiga dos músculos elevadores. Todos os pacientes recuperaram o padrão de atividade muscular normal após um mês da remoção das interferências oclusais.

De BOEVER; ADRIAENS ${ }^{19}$, em 1983 realizaram um trabalho com a proposta de estudar a possível relação entre a severidade dos sintomas de DTM e as características oclusais, particularmente com relação à presença de interferências oclusais. A análise de 135 pacientes, que buscaram tratamento para 
dor ou DTM, foi feita em três etapas: na primeira visita, após duas semanas e três semanas após a inserção da placa. Eles concluíram que a ocorrência de contatos prematuros no lado de não-trabalho causava maiores mudanças no padrão de contração muscular, refletindo em mudanças no movimento mandibular. No entanto, verificaram que a etiologia da dor ou DTM é complexa e que um simples fator oclusal parece não ser o responsável pelo problema, já que a perda dos molares e ocorrência de contatos prematuros não parecem influenciar na severidade da dor e/ou disfunção, mas podem ter um papel importante na resolução do tratamento.

SHEIKHOLESLAM; RIISE69, em 1983, avaliaram, em 11 indivíduos com idade entre 24 e 32 anos, o efeito de interferências oclusais experimentais no padrão de atividade dos músculos masseter e temporal anterior durante o fechamento e fechamento máximo. A atividade muscular foi registrada antes e após a instalação da interferência oclusal de $0,5 \mathrm{~mm}$ de altura nos tempos: antes, $1 \mathrm{~h}$ depois, 48h depois, uma semana após, imediatamente após a remoção e uma semana após. O registro bilateral era feito durante o fechamento (apertamento contínuo) e fechamento máximo (apertamento forte durante 1 segundo e relaxamento por 3 segundos como na mastigação). Os resultados desse estudo mostraram que: (1) durante a mordida e mordida máxima uma interferência oclusal em MIH é capaz de alterar o padrão simétrico da atividade muscular dos músculos masseter e temporal anterior; (2) o nível de atividade muscular diminuiu significativamente durante a mordida máxima; (3) o nível de atividade muscular diminuiu, na maioria dos indivíduos, 1 semana após a instalação das interferências; 
(4) a atividade muscular aumentou significativamente após a remoção das interferências oclusais experimentais. Os autores concluíram que os receptores periodontais podem modificar o padrão de atividade muscular dos músculos temporal e masseter durante mordida e mordida máxima. Além disso, distúrbios dos receptores periodontais, causados por interferências oclusais, podem levar a distúrbios do sistema estomatognático.

RIISE; SHEIKHOLESLAM ${ }^{66}$, em 1984, avaliaram, em 11 indivíduos com idade entre 24 e 32 anos, o efeito de IOE no padrão de atividade dos músculos masseter e temporal anterior durante a mastigação. A atividade muscular foi registrada bilateralmente durante os movimentos da mastigação (1) antes da instalação das IO de 0,5mm de altura; (2) 1h depois; (3) 48h depois; (4) uma semana após; (5) imediatamente após a remoção e (6) uma semana após. Os resultados desse estudo mostraram que pequenas interferências oclusais em $\mathrm{MlH}$ podem mudar a coordenação da atividade muscular durante a mastigação. Isso é perceptível uma vez que houve um tempo de contração prolongado bem como redução da atividade nos músculos elevadores estudados, especialmente no lado da interferência. Foi possível verificar também que, após $48 \mathrm{~h}$ com as 10 , os indivíduos optaram pela mastigação unilateral que retornava ao normal após a remoção das interferências.

DROUKAS; LINDÉE; CARLSSON²0, em 1984, avaliaram a possível influência de alguns fatores oclusais, especialmente o padrão oclusal, no desenvolvimento de sinais e sintomas de DTM em adultos assintomáticos. Foram 
estudados 48 indivíduos com idade média de 25 anos de ambos os sexos. Foram realizados registros dos sintomas subjetivos através de questionário e exame clínico para classificar os pacientes de acordo com o índice de disfunção de Helkimo. As variáveis oclusais registradas foram: contatos oclusais em $\mathrm{MIH}$, contato em posição de $\mathrm{RC}$, contatos em movimentos laterais em $\mathrm{RC}$ e $\mathrm{MIH}$ e desgastes oclusais. As interferências oclusais foram registradas nas seguintes posições: contato unilateral em $\mathrm{RC}$, deslize de $\mathrm{RC}$ igual ou maior que $2 \mathrm{~mm}$ no sentido vertical e horizontal, interferência no lado de não trabalho direito e esquerdo que impediram o contato no lado de trabalho e contato unilateral na protrusiva. Os resultados mostraram uma pequena freqüência dos sintomas subjetivos, sendo o ruído articular o mais comum deles (19\%). Os achados clínicos mostraram que 40\% dos indivíduos apresentaram dor muscular à palpação e 35\% danos na articulação, principalmente estalidos. Houve uma grande variação dos contatos oclusais nas várias posições de oclusão. A distância entre $\mathrm{RC}$ e $\mathrm{MIH}$ foi geralmente pequena com 12 registros de $2 \mathrm{~mm}$ ou mais no sentido vertical. O desgaste dentário, na sua maioria, ficou confinado ao esmalte na maioria dos dentes, no entanto $40 \%$ dos indivíduos apresentaram lesões na dentina. Nenhum tipo específico de padrão oclusal teve influência significativa nos sinais e sintomas de DTM neste grupo. Os autores concluíram que esses resultados suportam o conceito de etiologia multifatorial para as DTMs, sendo o fator oclusal o de menor importância.

MAGNUSSON; ENBOM, em $1984^{46}$, estudaram, durante duas semanas, os efeitos de interferências oclusais no lado de não-trabalho, em 24 
indivíduos saudáveis No grupo experimental, foram instaladas interferências bilaterais no lado de não-trabalho, enquanto o grupo controle recebeu uma simulação de interferência. Os resultados mostraram que, no grupo experimental, 10 indivíduos relataram sintomas subjetivos e 7 apresentaram sinais clínicos de DTM, enquanto no grupo controle, 3 indivíduos apresentaram sinais clínicos de DTM. Os autores concluíram que não existe relação entre a interferência oclusal e DTM, já que as DTMs podem ser desenvolvidas sem a existência de interferências oclusais. Segundo os autores, a resposta fisiológica de cada indivíduo aos fatores oclusais locais é o fator mais importante para se desenvolver DTM.

\section{EGERMARK-ERIKSSON; CARLSSON; MAGNUSSON ${ }^{23}$, em} 1987, através de um estudo longitudinal em crianças e adolescentes, verificaram a relação entre fatores oclusais e DTM com enfoque especial para oclusão e algumas condições de DTM. Foram avaliadas 402 crianças nas faixas etárias de 7, 11, 15 anos. Um questionário focado nos sintomas de DTM, parafunção, hábitos durante a mastigação e dor de cabeça era aplicado em conjunto com um exame clínico para detectar sinais de DTM e as condições oclusais, especialmente interferências oclusais e desgastes dentários. Os resultados mostraram a presença de diversos tipos de IOs. Mais da metade dos indivíduos com 11 anos ou mais velhos tinham pelo menos um contato unilateral em $\mathrm{RC}$ ou durante o desvio lateral da mandíbula entre RC e MIH. Entre 15 e 30\% não possuíam interferência no lado de não-trabalho quando se registravam movimentos excursivos laterais máximos. No entanto, a freqüência das interferências oclusais era bem menor durante a excursão lateral 
funcional (mais de $3 \mathrm{~mm}$ da $\mathrm{MlH}$ ). Ainda com relação æ̀ $\mathrm{IOs}$, não houve nenhuma diferença entre meninos e meninas. Com relação ao desgaste dentário, não houve aumento significativo de sua severidade durante o período de acompanhamento em todos os grupos de idade e em todas as regiões. Com relação aos sinais de DTM, houve um ligeiro aumento na freqüência e na severidade. A análise dos resultados mostrou que a correlação dos dados era pouco significativa, sendo, na maioria das vezes, fraca. Os ruídos articulares foram positivamente correlacionados com o desvio lateral da mandíbula e contato em $\mathrm{RC}$ e $\mathrm{MIH}$ em todas as idades. Uma tentativa a longo prazo de se correlacionar 10 com sinais e sintomas de DTM não demonstrou ser positiva. Finalmente, a interpretação dos resultados sugere a heterogeneidade e a natureza multifatorial dos distúrbios funcionais do sistema mastigatório.

PULLINGER; SELIGMAN; SOLBERG ${ }^{57}$, em 1988, estudaram a freqüência de sintomas de DTM e sua relação com as variáveis oclusais em 222 estudantes. Os fatores oclusais como a magnitude do desvio entre $\mathrm{RC}$ e $\mathrm{MIH}$ bem como os contatos dentários foram registrados em RC, através de manipulação passiva, para serem posteriormente relacionados com dor e DTM. Eles observaram que $29 \%$ dos pacientes apresentaram ruídos na articulação e $32 \%$ apresentaram dor muscular severa nos músculos temporal anterior e posterior. A amostra apresentou deslize de RC e $\mathrm{MIH}$ em $71 \%$, sendo que apenas $10 \%$ apresentaram deslizes maiores ou iguais a $1 \mathrm{~mm}$. 
PULLINGER; SELIGMAN; SOLBERG, em $1988^{68}$, realizaram uma revisão sobre a influência dos contatos nos lados de trabalho e não-trabalho, grau de deslize entre $\mathrm{RC}$ e $\mathrm{MIH}$, padrão de guias oclusais, parafunção e atrição dentária nas DTMs. Os autores concluíram que os estudos falharam em demonstrar a relação direta entre interferências oclusais e DTMs e que o deslize de RC para $\mathrm{MIH}$ pode ser um fator de risco para certos pacientes. Afirmam, também, que os padrões das guias oclusais influenciam os níveis de atividade muscular, mas não parecem provocar DTM.

No mesmo ano, SELIGMAN; PULLINGER; SOLBERG ${ }^{58}$ associaram os fatores oclusais com sensibilidade na ATM e disfunção em 222 estudantes. Os autores concluíram que a influência da oclusão no desenvolvimento das disfunções da ATM é limitada e que a diferença entre RC e MIH parece ser uma função protetora para o sistema estomatognático.

AGERBERG; SANDSTROM ${ }^{01}$, em 1988, examinaram 60 adolescentes com idade média de 15 anos e 80 adultos com idade média de 22 anos para verificar a freqüência de contatos e interferências oclusais em indivíduos sem história de DTM ou dor no sistema estomatognático. O contato entre os dentes superiores e inferiores e a ocorrência de interferências oclusais foram examinados e registrados em relação central. Eles encontraram que $25 \%$ dos indivíduos de ambos os grupos apresentaram contatos bilaterais simultâneos em relação central, e 75\% dos indivíduos apresentaram interferências oclusais distribuídas nos lados direito e esquerdo. Os dentes responsáveis pelas interferências na posição de relação 
central, em ambos os grupos, foram os pré-molares e os primeiros molares. As interferências ocorreram em maior número nos primeiros pré-molares e primeiro molar do grupo jovem e nos segundos pré-molares do grupo adulto.

A relação central também pode ser denominada de relação cêntrica ou posição de contato retruído e, mais recentemente, de posição de estabilidade ortopédica. OKESON, em $1989^{52}$, definiu esta posição como a relação maxilo-mandibular onde os côndilos estão apoiados sobre as vertentes posteriores das eminências articulares, com os discos articulares devidamente interpostos. $O$ autor verificou que a $\mathrm{RC}$ é uma posição estritamente relacionada à posição condilar, não apresentando nenhuma relação com a posição ou contatos dentários.

RUNGE ${ }^{65}$, em 1989, avaliou 256 pacientes, antes do tratamento ortodôntico, com o objetivo de verificar o relacionamento entre sons articulares e oclusão. Os fatores oclusais avaliados foram: (1) contatos oclusais unilaterais e bilaterais, nos dentes posteriores e anteriores, na posição de $\mathrm{MIH}$; (2) contatos oclusais de trabalho e não-trabalho durante os movimentos excursivos; (3) contatos em RC e (4) desgastes dentários. O resultado desse estudo revelou que 36,3\% dos pacientes apresentaram ruído articular, sendo este estatisticamente maior com o aumento da idade. Não houve associação estatisticamente significativa entre a presença de ruído articular, história de dor e limitação de movimento. Também não houve nenhuma associação estatisticamente significativa entre a presença ou ausência de ruídos articulares e qualquer um dos fatores oclusais estudados. 
McGLYINN et al. ${ }^{47}$, em 1989, através de questionário, exame clínico e articulador, avaliaram quinze indivíduos sem história de DTM. Esse estudo teve a finalidade de avaliar o efeito das interferências oclusais experimentais na atividade eletromiográfica dos músculos masseter. As interferências oclusais foram realizadas através da instalação de restaurações totais nos segundos molares superiores de cada indivíduo, sendo uma para produzir interferência apenas no lado de não-trabalho, e outra como controle do lado de trabalho.Foram registrados dados sobre dor muscular, ruídos articulares, limitações na abertura e dor durante a função. A atividade eletromiográfica foi verificada bilateralmente antes e após a instalação das interferências oclusais. A avaliação clínica realizada em RC e MIH verificou a presença de faceta, mobilidade dentária, ruídos articulares, dor à palpação muscular e a presença de infecções, nos dois lados estudados. Após análise dos dados, os autores concluíram que: (1) as coroas experimentais só produziram IO no lado de não trabalho durante a função; (2) a presença de irritação gengival e dor dentária localizada ocorreu provavelmente por desadaptação das coroas e (3) não foi possível provar que o aumento da atividade eletromiográfica do músculo masseter ocorreu pela presença de $\mathrm{IO}$.

KIRVESKARI; ALANEN; JAMSA ${ }^{40}$, em 1989, verificaram a associação entre a presença de interferências oclusais e sinais e sintomas de DTM. O estudo avaliou 53 crianças que receberam ajuste oclusal e 46 crianças que receberam tratamento placebo. Foi considerado que as interferências estariam presentes quando houvesse diferença de $\mathrm{RC}$ e $\mathrm{MIH}$, contato unilateral em $\mathrm{RC}$, 
contato no lado mediotrusivo,contato em canino em movimento protrusivo e contato posterior no lado de laterotrusão. A análise dos sintomas foi feita por meio de questionário e análise clínica da sensibilidade muscular, dor em abertura máxima e ruídos articulares durante o movimento. Após dois anos, encontrou-se uma associação estatisticamente significativa, sendo que os sinais subjetivos também estavam associados aos sinais de DTM. No entanto, o estudo não foi capaz de responder se as interferências são uma parte necessária na complexa etiologia das disfunções, já que outros fatores coadjuvantes são necessários para o desenvolvimento das DTMs.

SELIGMAN; PULLINGER ${ }^{67}$, em 1991, realizaram uma revisão da literatura sobre o papel do relacionamento oclusal no desenvolvimento das DTMs. Observaram que a presença de sintomas mais severos, relacionados à presença de contatos unilaterais em RC, ocorreu na população adulta. No entanto, esses achados não puderam ser confirmados pelos estudos avaliados, os quais geralmente não tinham controle sobre a idade. Observaram, ainda, que muitos estudos associaram contatos unilaterais em $\mathrm{RC}$ com a presença de estalido nas articulações ou com outros fatores relacionados a DTM, estabelecendo ser prudente o ajuste oclusal nestes casos, sempre que possível. Nas populações mais velhas, essa associação não foi observada, indicando que na ausência de sintomatologia o ajuste oclusal é desaconselhável como método preventivo. Outro fato a ser considerado é que o atrito dentário pode reduzir a prevalência de contatos unilaterais em RC. 
KIRVESKARI; ALANEN; JAMSA ${ }^{41}$, em 1992, através de um estudo longitudinal de cinco anos, verificaram a associação entre sinais clínicos de DTM e 10 em 202 crianças de cinco anos e 138 de dez anos. As crianças foram divididas aleatoriamente em quatro grupos iguais, sendo dois grupos controle e dois experimentais. As avaliações foram realizadas anualmente pelo mesmo examinador quanto à presença de sinais de DTM e número de interferências oclusais. O exame físico consistia de palpação muscular e articular, ruídos articulares e movimentação mandibular, enquanto o exame clínico consistiu de mensuração do desvio de RC para MIH no sentido vertical e horizontal e a presença de contato do lado de nãotrabalho. O deslize de RC para MIH no sentido vertical e horizontal apresentou magnitude máxima de $1 \mathrm{~mm}$. Após o primeiro exame, as crianças foram submetidas a ajuste oclusal real ou placebo. Os resultados mostraram que: (1) não foi possível distinguir os pacientes ajustados dos não ajustados sem o exame detalhado da superfície oclusal, no entanto ocorreram muitas evidências de redução do número de interferências; (2) a associação entre o número de $\mathrm{IO}$ e a presença de sinais de DTM foi significativa nos dois grupos controles.

KARLSSON; CHO; CARLSSON ${ }^{36}$, em 1992, estudaram as mudanças no padrão do movimento mastigatório através da inserção de interferências oclusais experimentais no lado de não-trabalho. Afirmaram que houve variações na amplitude de abertura e velocidade do movimento. No entanto, a influência das interferências oclusais nos músculos analisados não representaram um obstáculo ao funcionamento normal dos músculos mastigatórios, ou ainda que os 
pacientes estavam bem adaptados à situação oclusal. Eles concluíram que o sistema mastigatório apresenta uma alta capacidade adaptativa através do sistema neuromuscular, frente às interferências oclus ais, logo após uma semana.

Em 1993, KVINNSLAND; KVINNSLAND; KRISTIANSEN ${ }^{42}$ estudaram o efeito das interferências oclusais nas articulações temporomandibulares de ratos com a finalidade de observar o efeito da oclusão traumática na vascularização da articulação. Foram utilizadas interferências de $1 \mathrm{~mm}$ de altura nos primeiros molares direitos de 30 ratos. Antes de serem sacrificados, 1, 5, 10, 15 e 20 dias após a instalação das interferências, as cobaias receberam uma injeção de microesferas fluorescentes na ATM. Os resultados mostraram que, após 15 a 20 dias de interferências oclusais, houve um aumento na vascularização da ATM do mesmo lado da interferência. Quando comparados com o grupo controle, houve também um aumento da vascularização em ambos os lados em bdos os animais experimentais. Eles interpretaram esses resultados como uma demonstração de que as interferências oclusais são capazes de alterar as cargas recebidas pelas articulações.

WESTLING ${ }^{75}$, em 1995, avaliou 193 adolescentes assintomáticos para verificar se interferências oclusais unilaterais em $\mathrm{RC}$ foram mais freqüentes em meninas que em meninos. Verificaram, também, se as IOs eram mais freqüentes em indivíduos com e sem estabilidade articular. O registro dos ruídos articulares foi realizado pela auscultação e palpação manual durante os movimentos de abertura e fechamento. Os estalidos foram classificados em: estalido recíproco, 
estalido não recíproco e estalido tardio. O registro das interferências oclusais foi realizado quando os contatos verticais foram maior ou igual a $1 \mathrm{~mm}$ e os horizontais maiores que $0,5 \mathrm{~mm}$. Os resultados mostraram que: (1) $48 \%$ dos indivíduos apresentaram contatos unilaterais em RC; (2) os contatos unilaterais em RC foram significativamente mais freqüentes nas meninas que nos meninos; (3) $67 \%$ dos indivíduos com hipermobilidade articular tiveram contatos unilaterais em RC; (4) os ruídos articulares foram clinicamente observados em $33 \%$ dos adolescentes e (5) os ruídos articulares tiveram pequena correlação com distância vertical maior ou igual a $1 \mathrm{~mm}$. Os resultados mostraram que somente o ruído articular não recíproco foi relacionado com as medidas verticais maior ou igual a $1 \mathrm{~mm}$. Respostas afirmativas para as questões sobre dor no movimento foram relacionadas com a presença de contatos unilaterais em RC. Nenhuma diferença ocorreu entre os sexos na distribuição de estalidos recíprocos e não recíprocos e a distância vertical de RC para $\mathrm{MIH}$. O autor concluiu que contatos unilaterais em RC podem ser considerados um fator predisponente para dstúrbios articulares e que fatores adversos podem interferir na medida vertical entre $\mathrm{RC}$ e $\mathrm{MIH}$.

RICHARDIN et al., em $1995^{61}$, instalaram interferências oclusais experimentais de 2 alturas (alta e baixa) bilateralmente em 12 ratos, para medir a atividade eletromiográfica dos músculos temporal anterior, masseter superficial e digástrico anterior. Como resultado, os autores encontraram um aumento da atividade eletromiográfica nos músculos temporal anterior e masseter superficial durante a fase de abertura tardia, o que não foi observado no grupo 
controle. Os resultados mostraram que uma alteração do esquema oclusal pode ser deletéria para a articulação além de alterar a função dos músculos da mandíbula. No entanto, esse estudo não explicou se essas mudanças são respostas adaptativas normais ou se o começo de uma disfunção crônica. Além disso, não se sabe se os efeitos das interferências nesses animais podem ser extrapolados para os humanos devido ao fato de serem bastante altas. Outro fato a ser considerado é que cirurgias ortognáticas podem mudar bruscamente o esquema oclusal e, no entanto não causando alterações patológicas nas articulações, e apenas remodelação das mesmas.

CHRISTENSEN; RASSOULI' ${ }^{16}$, em 1995, estudaram, através da atividade eletromiográfica em repouso e em função, o efeito que uma interferência oclusal unilateral tem nos músculos de ambos os lados da mandíbula. Foram realizadas 12 restaurações de resina, na região de segundos pré-molares e primeiros molares, com altura de 0.24 a $0.21 \mathrm{~mm}$. O registro da atividade eletromiográfica nos músculos masseter foi realizado com o paciente em atividade e em repouso antes e após a instalação das interferências oclusais. A análise dos resultados mostrou: (1) um aumento da atividade eletromiográfica dos músculos masseter durante a função, com e sem a interferência; (2) um aumento de 121\% mais ou menos $69 \%$ no lado da interferência e (3) um aumento de $86 \%$ mais ou menos $19 \%$ no lado contrário da interferência. No entanto, esses aumentos não foram considerados significativos. 
EGERMARK; RONNERMAN²4, em 1995, observaram a correlação entre os sinais e sintomas de DTM antes e após o tratamento ortodôntico. O grupo experimental era constituído de 50 pacientes, sendo 23 meninos e 27 meninas, com idade média de 12,9 anos. Os pacientes realizaram tratamento ortodôntico com aparelho fixo e removível, com e sem extração dos pré-molares. O grupo controle era constituído de 135 pacientes com idade média de 15 anos. Foram realizados questionários a respeito dos diferentes sinais e sintomas de DTM (ruídos na ATM, dificuldade de abrir a boca, cansaço mandibular, dor de cabeça, apertamento e bruxismo). As interferências oclusais foram detectadas na posição de $\mathrm{RC}$, e durante a função somente no lado de não-trabalho. Esse estudo mostrou que houve uma alta prevalência de sinais e sintomas de DTM nos pacientes antes do tratamento ortodôntico, no entanto não foram muito severos. Durante a fase ativa do tratamento ortodôntico e durante a fase de contenção, houve redução dos sinais e sintomas de DTM. Para determinar se esse fato é temporário ou permanente, necessita-se de investigações em estudos longitudinais.

MCNAMARA, SELIGMAN e OKESON ${ }^{48}$, em 1995, em uma revisão da literatura, relataram que deslizes menores que $1 \mathrm{~mm}$ foram comuns na maioria dos pacientes e que deslizes maiores que $2 \mathrm{~mm}$ foram encontrados em pacientes com algum tipo de desordem. Com esse trabalho, afirmaram que o deslize entre RC e MIH não parece contribuir para o aparecimento de DTM, sendo desnecessária a eliminação profilática dessas interferências. Na verdade, os autores relatam que apesar de todos os caminhos levarem a acreditar que as interferências 
causam as DTMs, eles acreditavam que as discrepâncias entre $\mathrm{RC}$ e $\mathrm{MIH}$, maiores que $2 \mathrm{~mm}$ eram conseqüência e não causa de DTM.

CONTI et al. $^{14}$, em 1996, estudaram a prevalência e necessidade de tratamento das DTMs, bem como o papel da oclusão e de fatores emocionais no desenvolvimento das mesmas. Foram avaliados 310 estudantes divididos em dois grupos. O primeiro grupo foi composto de 152 estudantes do colegial, com idade média de 18 anos, e o segundo grupo foi constituído de 158 estudantes universitários, com idade média de 21anos. A avaliação foi realizada através de questionário, palpação articular e muscular e avaliação da oclusão, para verificar a presença de contatos em $\mathrm{RC}$ e em $\mathrm{MIH}$, verificar o trespasse vertical e horizontal, verificar movimentos excursivos da mandíbula (protrusivos e laterais) e supracontatos em não-trabalho. Os resultados mostraram que não houve diferença na severidade de DTM, entre os grupos, apesar de os estudantes universitários terem se classificados como mais tensos. Quanto à necessidade de tratamento, somente $35 \%$ dos pacientes apresentaram necessidade de intervenção independente do grupo. O posicionamento maxilomandibular mostrou que $20,65 \%$ dos pacientes apresentaram $\mathrm{RC}$ coincidente com MIH. Supracontatos no lado de não-trabalho, foram detectados em $22,58 \%$ dos indivíduos. Nenhum relacionamento entre fatores oclusais e a presença e severidade de sinais e sintomas de DTM foi encontrado. A oclusão pareceu não influenciar na presença ou severidade das DTMs. Os autores concluíram baseados nesses resultados, que a eficácia de muitos 
tratamentos deveria ser reconsiderada e procedimentos reversíveis e conservadores deveriam ser a primeira escolha para o tratamento desses pacientes.

BABA et al., em $1996^{04}$, estudaram o efeito da interferência oclusal na atividade dos músculos mastigatórios, durante a mastigação, em várias posições. Eles utilizaram 3 tipos de interferências oclusais, com altura desconhecida, em 12 indivíduos normais. Os tipos de interferência utilizados foram: (1) aumento do canino superior direito; que desocluia todos os outros dentes durante os movimentos excêntricos da mandíbula para o lado direito, (2) interferência no segundo molar do lado de trabalho e (3) interferência nos segundos molares do lado de não-trabalho.Os registros da atividade eletromiográfica foram realizados, antes e imediatamente depois da instalação da interferência, bilateralmente nos músculos masseter e temporal anterior e posterior, durante a mastigação máxima, por 2 segundos, e quando o canino direito estava na posição de topo a topo. Os resultados mostraram que, com interferência oclusal no lado de trabalho, a atividade eletromiográfica dos músculos temporal anterior e posterior, durante a mastigação máxima, aumentou e no lado de não-trabalho diminuiu. Para o músculo masseter, a atividade permaneceu a mesma.

WATANABE et al. ${ }^{73}$, em1998, avaliaram o relacionamento entre sinais e sintomas de DTM e o padrão de contato oclusal bilateral em 143 pacientes com DTM. Foram realizados exames clínicos de palpação muscular e exame do padrão de contato oclusal de cada paciente, através de movimentos excursivos laterais em ambas as direções. Os contatos foram marcados com papel 
carbono para verificar se havia contatos oclusais nos dentes anteriores durante os movimentos excursivos. Quando presentes, os contatos oclusais foram classificados em: (1) contato no lado de trabalho, (2) contato no lado de não trabalho e (3) contato bilateral (trabalho e não-trabalho). Os resultados mostraram que as queixas mais freqüentes de DTM foram: (1) dor muscular $(74,8 \%)$, (2) dificuldade de abertura (46,8\%), (3) ruído articular (40,5\%), (4) dificuldade na mastigação (4,9\%) e (5) outros $(8,4 \%)$. O padrão de contato oclusal mais comum foi o contato no lado de trabalho $(75,9 \%)$, seguido de contatos bilaterais $(18,5 \%)$ e contatos do lado de não trabalho (5,6\%). Concluiu-se que existe uma pequena relação entre a sintomatologia de DTM e o padrão de contatos oclusais durante os movimentos excursivos laterais, mas também foi sugerido que poucos sinais e sintomas de DTM podem estar associados com contatos oclusais particulares.

IKEDA et al. ${ }^{32}$, em 1998, verificaram a influência de IOE na sensibilidade dentária de cinco indivíduos com idade média de 27 anos sem história de DTM. As IOE foram realizadas através de restaurações do tipo inlay, instaladas na região de pré-molares e molares, na posição de $\mathrm{MIH}$, sem interferir nos movimentos laterais, com altura variando entre $75 \mu \mathrm{m}$ a $280 \mu \mathrm{m}$. A sensibilidade dentária foi mensurada cinco vezes por dia, através de estimulação elétrica, antes e durante a aplicação das IOE e após o ajuste. Os resultados mostraram uma diminuição significativa do limiar de dor após a instalação das IOE quando comparados com os pacientes que receberam restaurações ajustadas.Foi possível observar ainda que os contatos prematuros menores que $200 \mu \mathrm{m}$ foram capazes de 
induzir hipersensibilidade dentinária e que a remoção desses foi o tratamento mais efetivo para remissão dos sintomas. Finalmente, os autores concluíram que a sensibilidade ocorre na maioria dos dentes submetidos a trauma oclusal e, que se o ajuste for realizado, o dente recuperará sua condição normal. Se o ajuste não for realizado, poder ocorrer uma intrusão fisiológica decorrente das forças oclusais.

CLARK et al. $^{12}$, em 1999, realizaram uma revisão da literatura sobre interferências oclusais experimentais em dezoito estudos realizados em humanos e dez em animais. Observaram que a presença de interferências oclusais pode causar dor dentária localizada, alteração nos níveis de tensão dos músculos posturais, mudanças nos movimentos mastigatórios e, algumas vezes, a indução de estalidos articulares. No entanto, por esses achados estarem presentes em pacientes assintomáticos, afirmaram que não se pode provar a relação entre interferências oclusais e dor muscular crônica ou alterações disfuncionais na ATM.

KAHN et al. $^{35}$, em 1999, avaliaram a prevalência do relacionamento molar, guia lateral, contatos de não-trabalho e DTM em 82 voluntários assintomáticos e 263 pacientes sintomáticos, com dor localizada na articulação ou dor durante a função, estalidos articulares e alguma história positiva de DTM. Os contatos do lado de não-trabalho foram avaliados quando os pacientes realizavam movimentos laterais excursivos de $3 \mathrm{~mm}$ para a direita ou para esquerda na posição de oclusão cêntrica. A presença de um contato do lado de não-trabalho, que impedisse os contatos do lado de trabalho, foi considerada interferência oclusal. Os resultados mostraram que o grupo de voluntários com articulação normal 
apresentou uma alta prevalência de um ou mais contatos no lado de não-trabalho quando comparados com pacientes sintomáticos com articulação normal e com deslocamento de disco. Esse estudo sugeriu que não existem diferenças oclusais dentárias que possam, separadamente, indicar o desenvolvimento de processos intra-articulares nas DTMs.

PULLINGER; SELIGMAN ${ }^{56}$, em 2000, avaliaram a influência que as variáveis oclusais como discrepâncias entre $\mathrm{RC}$ e $\mathrm{MIH}$, mordida cruzada posterior, overjet e overbite, desvio de linha média, podem apresentar para diferenciar pacientes com DTM de indivíduos normais assintomáticos. Observaram que a oclusão pode ser um co-fator na identificação de pacientes com DTM e que algumas variações representam uma conseqüência da disfunção.

CLARK; EVANS ${ }^{13}$, em 2001 realizaram uma revisão da literatura com o intuito de descrever as características que são realmente necessárias para uma oclusão ideal. Concluíram que uma oclusão ideal deve apresentar contatos bilaterais em relação central, deslize de $\mathrm{RC}$ para $\mathrm{MIH}$ inferior a $1 \mathrm{~mm}$, ausência de contatos no lado de não-trabalho e durante os movimentos excursivos, exceto pelo canino.

NISHIDE et al. ${ }^{51}$, em 2001, investigaram as alterações histológicas no músculo masseter de ratos após a instalação de interferências oclusais experimentais. A amostra consistiu de 8 ratos adultos, sendo 4 experimentais e 4 controle. $O$ grupo experimental recebeu restaurações de resina composta de $1 \mathrm{~mm}$ de altura na região de molares superiores. Todos os animais 
foram sacrificados após 4 semanas para análise histológica do músculo masseter profundo. Os resultados evidenciaram que, no grupo controle, o músculo masseter mostrou uniformidade no tamanho das fibras musculares com os núcleos localizados na periferia das fibras, não sendo observada a presença de fibras degeneradas em nenhum segmento. No grupo experimental, embora as fibras permanecessem intactas, foram observadas algumas mudanças como a presença de células inflamatórias nas fibras musculares. Um grande número de fibras apresentou núcleos centralizados o que caracteriza fibra em regeneração. A partir desses resultados, os autores puderam concluir que as interferências oclusais causam mudanças histológicas no músculo masseter e que isso pode ser observado pelo fato de o nível de energia muscular ter reduzido durante os movimentos mastigatórios no lado da interferência oclusal.

JOHN et al. ${ }^{34}$, em 2002, avaliaram em 208 pacientes sintomáticos e 172 assintomáticos se o desgaste dos dentes anteriores estava associado com DTM. Através do índice de severidade de PULLINGER \& SELIGMAN verificaram, em modelos de estudo, o grau de desgaste dos dentes. Os resultados mostraram que não houve associação entre desgaste dos dentes anteriores e DTM, uma vez que os sinais de desgaste estavam assimetricamente distribuídos entre o grupo controle e o grupo sintomático. Verificou ainda, que com o aumento da idade, o desgaste era maior nos homens do que nas mulheres.

BELL et al. ${ }^{06}$, em 2002, estudaram o papel das interferências oclusais como fator etiológico das DTMs em 52 mulheres, divididas em dois grupos, 
com idade variando de 19 a 42 anos. Um grupo era formado por 31 estudantes(14 controle e 12 com IOE) com boa saúde geral, ausência de DTM e dentes normais corrigidos por ajuste oclusal para eliminar interferências oclusais. O outro grupo era formado por 21 pacientes (11 controle e 10 com IOE) com história de DTM, já anteriormente tratada. As interferências oclusais foram colocadas bilateralmente nas cúspides palatinas do segundo molar superior do lado de não-trabalho, na posição de $R C$, nos dois grupos. A magnitude das interferências foi de $0,3 \mathrm{~mm}$ em $R C$ mensurada na região dos incisivos. O estudo revelou que nos indivíduos sem DTM, independente se controle ou experimental, não houve diferença estatisticamente significativa no número de sinais e sintomas. Os indivíduos com história de DTM apresentaram sinais e sintomas mais severos nos grupos com interferência, quando comparados com o grupo placebo. Todos os indivíduos com interferência mostraram um aumento dos sinais clínicos com seus respectivos grupos controle. $\mathrm{O}$ tamanho reduzido das interferências pode explicar porque indivíduos sem história de DTM relataram somente um pequeno desconforto. O tamanho das interferências oclusais também explica porque todos os indivíduos melhoraram depois da retirada das interferências. Os indivíduos com história de DTM tiveram mais sítios doloridos à palpação do que aqueles sem história DTM. É possível que a DTM ou o seu tratamento possam afetar indivíduos sensíveis e conscientes da oclusão, já que os indivíduos do grupo assintomáticos não tiveram variação da sensibilidade muscular. Esse estudo concluiu que indivíduos sem história de DTM apresentaram uma melhor adaptação æ̀s interferências experimentais. No entanto, os pacientes que 
apresentaram DTM tiveram uma grande variabilidade de sintomatologia. A diferença entre os grupos com e sem DTM sugerem que as interferências oclusais são um fator etiológico das DTMs.

FUJII ${ }^{25}$, em 2003, avaliou 71 pacientes sintomáticos divididos em dois grupos, com a finalidade de verificar a associação entre o lado de ocorrência do sintoma de dor ou ruído e o lado da interferência oclusal. O grupo 1 era constituído de 31 pacientes com dor muscular ou articular, e o grupo 2 era constituído de 40 pacientes com algum tipo de ruído articular. A análise da sintomatologia dolorosa, do ruído articular e da oclusão foi realizada na primeira consulta e após o tratamento para a remissão dos sintomas Os resultados mostraram que não há associação entre o lado em que ocorre a sintomatologia e o lado em que ocorre a interferência oclusal. Esses dados sugerem que dor muscular ou ruído articular não se desenvolvem no lado das interferências oclusais. 
Proposição 


\section{PROPOSIÇÃO}

De acordo com os dados da literatura, não está clara a relação de causa e efeito das interferências oclusais, no sentido vertical, com a presença de sinais clínicos de trauma oclusal e sinais e sintomas de DTM. Propõese com este trabalho:

Avaliar a magnitude das interferências oclusais e sua relação com os sinais clínicos de trauma oclusal e sinais e sintomas de Desordens Temporomandibulares. 
Material e Métodos 


\section{MATERIAL E MÉTODOS}

\subsection{AMOSTRA}

Com o objetivo de estudar a relação de causa e efeito entre a magnitude da interferência oclusal e a presença de sinais sintomas de trauma oclusal e sinais e sintomas de DTM, foram selecionados aleatoriamente 43 pacientes, independente do sexo e idade, entre os pacientes em tratamento nas clínicas da Faculdade de Odontologia de Bauru da Universidade de São Paulo. Para serem incluídos no estudo, os pacientes não poderiam ser desdentados totais ou apresentar ausência de 5 ou mais unidades oclusais posteriores não substituídas e não poderiam estar em tratamento ortodôntico.

\subsection{MATERIAL}

Os materiais utilizados para a avaliação foram:

a) Papel celofane;

b) Fita detectora de contatos (Accu-Film)*; 
c) Pinça de Miller;

d) Espelho clinico;

e) Acrilico Duralay vermelho (Pó e Líquido) ${ }^{\#}$;

f) Brocas para desgaste de acrilico;

g) Marcador para retro projetor;

h) Régua milimetrada.

\subsection{EXAME CLÍNICO}

Inicialmente, os pacientes selecionados preencheram uma ficha contendo os dados pessoais relacionados com nome, idade, sexo, endereço e telefone. Em seguida, um examinador previamente treinado e calibrado executou o exame clínico extra e intrabucal com a finalidade de detectar sinais e sintomas de DTM (dor muscular, dor e/ou ruidos articulares) e a presença de sinais clinicos de interferências oclusais (faceta mobilidade dentária, recessão gengival, abfraçăo e dor dentária localizada).

O exame extrabucal iniciou-se com a palpaçăo da musculatura da cabeça, do pescoço, palpação das ATMs e avaliaçăo da presença de ruidos articulares. O exame de palpaçāo muscular foi realizado com palpaçăo digital

\footnotetext{
${ }^{*}$ Duralay @ (Reliance dentalNfg Co., Illinois, U.S.A).
} 
bilateral, exercendo uma pressão constante. A presença de dor era constatada diante do reflexo palpebral e/ ou questionamento ao paciente. A presença de sintomatologia dolorosa na ATM foi detectada através de palpação digital bilateral com os dois dedos indicadores colocados 10 a $20 \mathrm{~mm}$ à frente do conduto auditivo externo. O aspecto lateral da ATM foi palpado com o paciente de boca fechada e o aspecto posterior, com o paciente de boca aberta, de maneira delicada e contínua ${ }^{3}$. A presença de ruídos articulares nas ATMs foi considerada quando o estalido se repetisse por três vezes ${ }^{22}$. Essa avaliação foi realizada posicionando-se os dedos indicadores na região correspondente ao pólo lateral do côndilo, à frente do meato acústico externo, enquanto o paciente realizava movimentos de abertura e fechamento mandibular.

O exame intrabucal iniciou-se com a análise dos dentes para pesquisa de sinais clínicos de interferências oclusais (faceta, mobilidade dentária, recessão gengival, abfração e dor dentária localizada).

Em seguida, foi confeccionado um dispositivo desprogramador denominado "JIG de Lucia" ${ }^{21}$ que provoca o relaxamento muscular do paciente e possibilita uma manipulação para a posição de $\mathrm{RC}$, livre de reflexos e propriocepção. Antes da confecção desse dispositivo, os dentes anteriores foram protegidos com papel alumínio e vaselina (figuras 1 e 2). A resina acrílica (Duralay vermelho) para confecção do JIG foi trabalhada na fase borrachóide para permitir modelação (figura 3). Após a polimerização foram feitos recortes criando-se uma crista central na qual se daria o único contato que impediria qualquer contato 
dentário (figura 4). Nessa posição, o primeiro contato dentário interferente permaneceu afastado aproximadamente $1 \mathrm{~mm}$ do seu antagonista (figura 5 e 6). Após a instalação do "JIG", o paciente ficou em repouso por quinze minutos até que ocorresse um relaxamento muscular que possibilitasse a manipulação da mandíbula para a posição de RC.

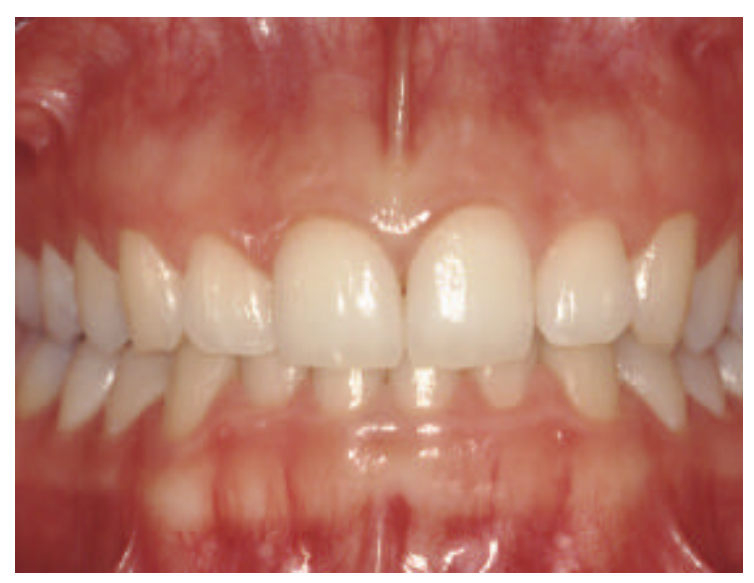

Figura 1: proteção dos dentes com vaselina para confecção do JIG.

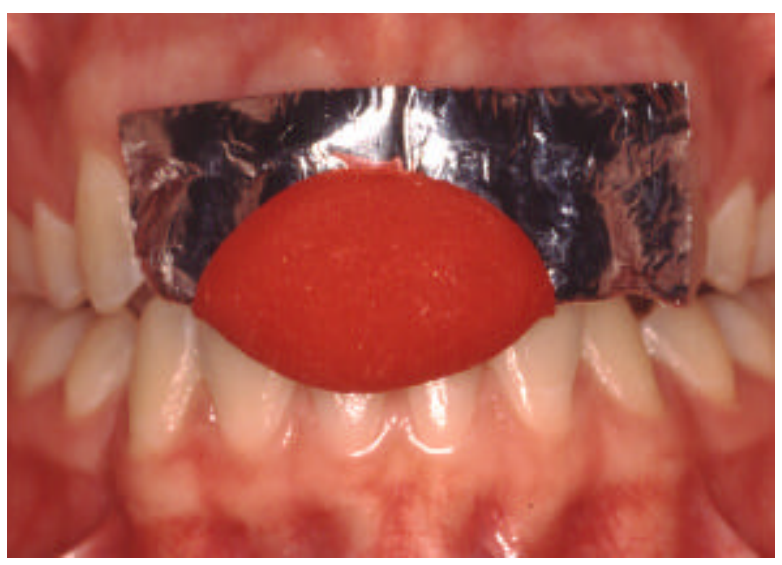

Figura 3: resina acrílica na fase borrachóide para modelação para confecção do JIG.

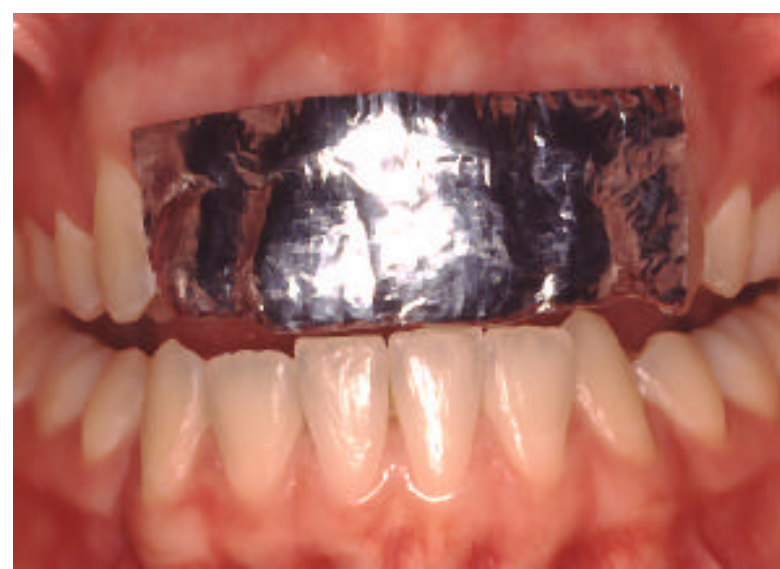

Figura 2: proteção dos dentes com papel alumínio para confecção do JIG.

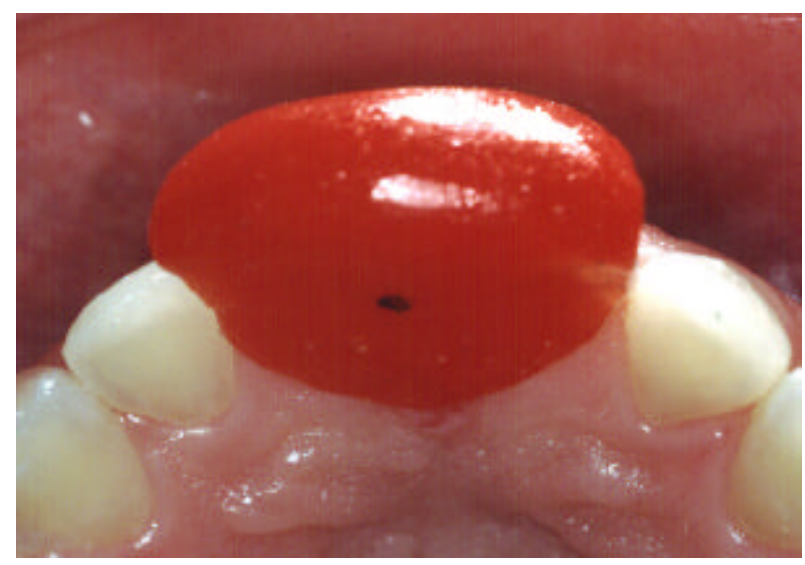

Figura 4: contato único no JIG. 


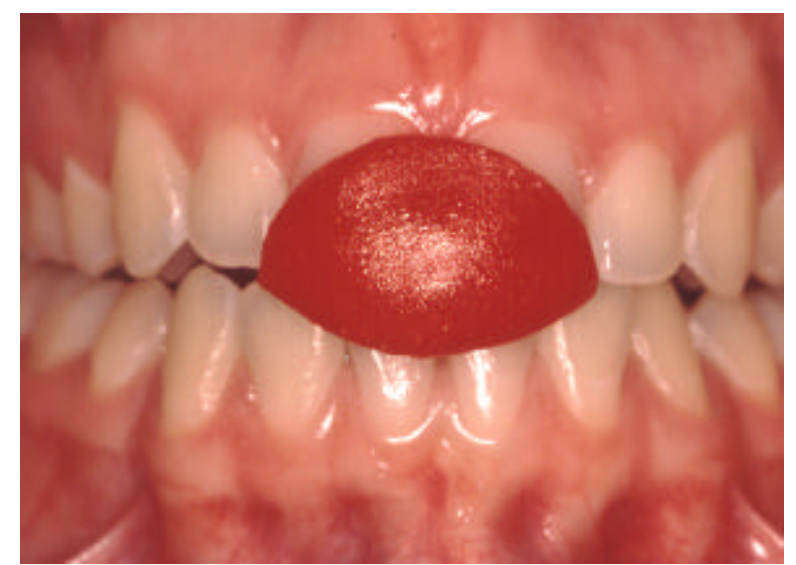

Figura 5: contato único no JIG para impedir qualquer contato dentário.

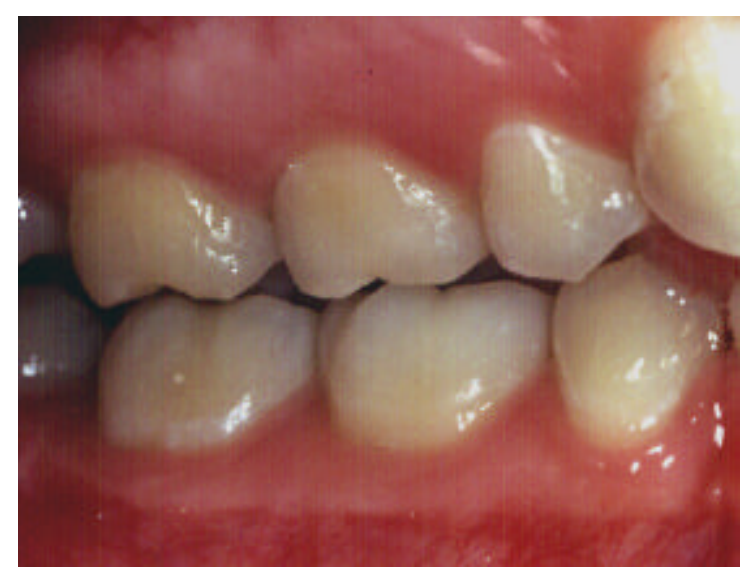

Figura 6: contato interferente distante aproximadamente $1 \mathrm{~mm}$ do seu antagonista.

Durante a manipulação, o examinador posicionava-se imediatamente atrás da cabeça do paciente, com os quatro dedos de cada mão suavemente apoiados na borda inferior da mandíbula para posicioná-la para cima, sem produzir desconforto. Em seguida, apoiavam-se os dedos polegares sobre a depressão da sínfise mentoniana exercendo pressão para baixo e para trás. Quando a mandíbula movimentava-se livremente sob o comando do operador, uma pressão final era exercida para cima e para trás. A combinação suave desses movimentos evitava o reflexo postural do paciente posicionando o côndilo no eixo terminal, que é conhecido como posição de Relação Central. Durante a manipulação, o paciente deveria permanecer relaxado, em posição supina com a cabeça estabilizada, para 
que não se movesse durante a manipulação, e reclinada para trás com a finalidade de se eliminar a tendência de protrusão da mandíbula.

Finalmente, o paciente era orientado a repetir essa posição durante abertura e fechamento para que pudesse repeti-la sem o auxílio do "JIG". A partir do momento que o paciente conseguisse posicionar a mandíbula na posição de RC, sem o auxílio do JIG, era possível determinar corretamente a localização e magnitude do contato de interferência. O registro da magnitude do contato de interferência foi feito na borda incisal do incisivo superior, na face vestibular do incisivo inferior, nas posições de $\mathrm{MIH}$ e contato interferente. A diferença em milímetros dessa posição determinou a magnitude da interferência. Para descrever os resultados, a magnitude das interferências oclusais foi dividida em interferências menores ou iguais a 2,5mm e interferências maiores que $2,5 \mathrm{~mm}$.

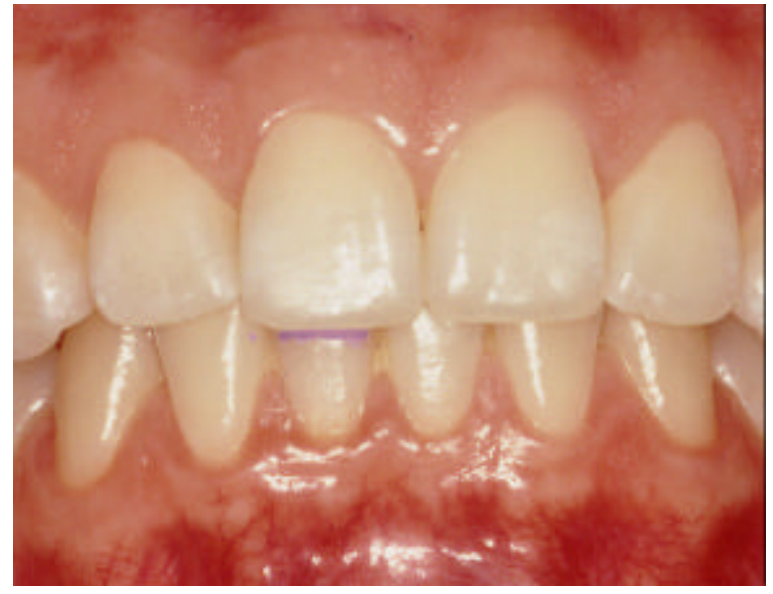

Figura 7: registro da borda incisal do incisivo superior, na face vestibular do incisivo inferior, na posição de $\mathrm{MIH}$.

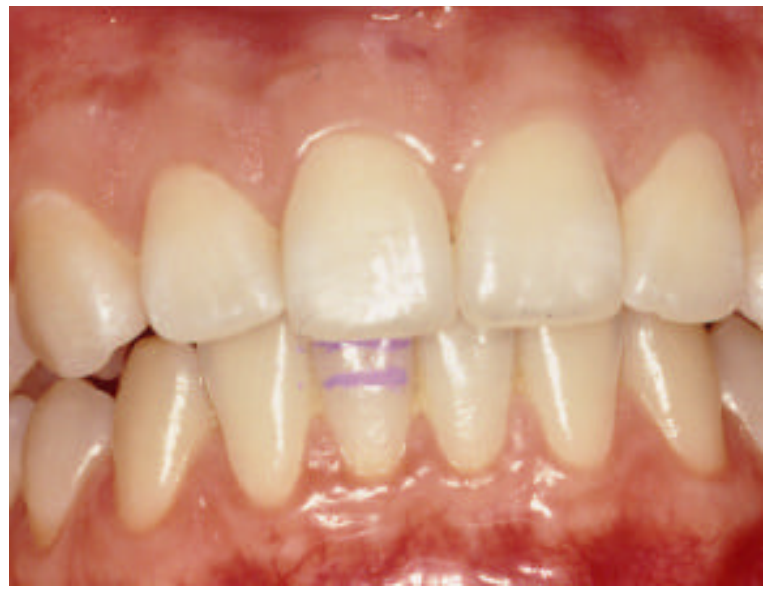

Figura 8: registro da borda incisal do incisivo superior, na face vestibular do incisivo inferior, na posição de RC. 


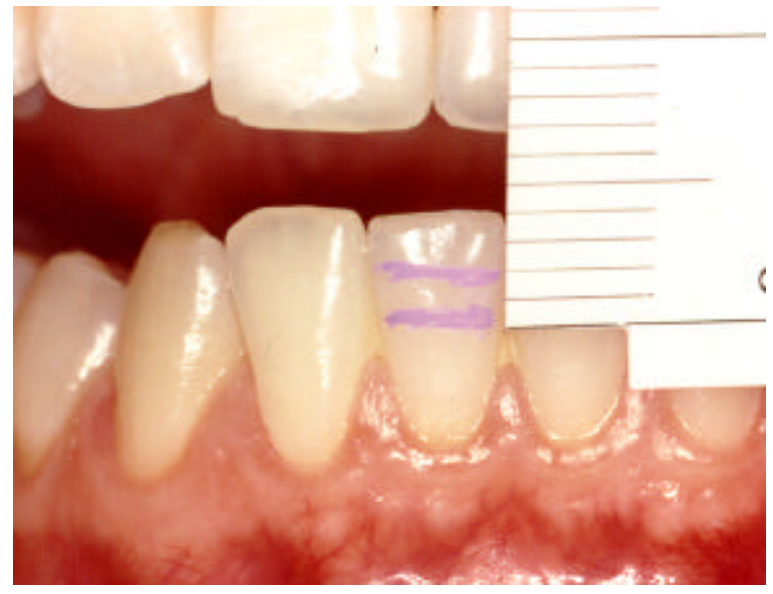

Figura 9: registro da magnitude da interferência oclusal.

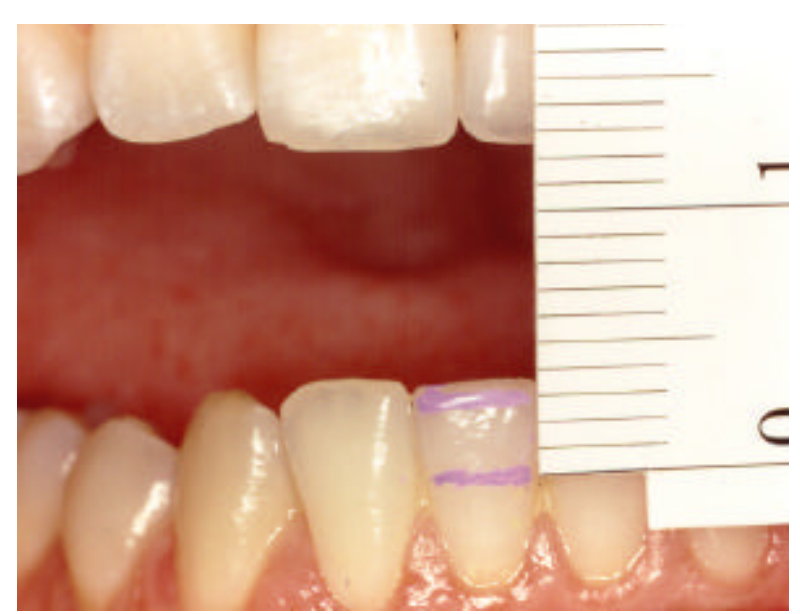

Figura 10: registro da magnitude da interferência oclusal.

Os dados obtidos foram anotados em ficha clínica específica (anexo 1).

\subsection{ANÁLISE ESTATÍSTICA}

As freqüências das diversas variáveis analisadas foram expressas em percentual através da estatística descritiva.

Para a análise de inferência dos resultados, foi aplicado o teste "t" de Student $(\mathrm{p}<0,05)$ para comparar a magnitude da interferência oclusal com os sinais e sintomas de DTM e sinais clínicos de trauma oclusal. O teste exato de Fisher $(p<0,05)$ foi utilizado para verificar: (1) a associação entre sexo e dor muscular, dor articular e presença de ruídos articulares; (2) a associação entre 
evidências de interferência oclusal e dor muscular, dor articular e presença de ruído articular e (3) a associação entre a magnitude da interferência oclusal e dor muscular, dor articular, presença de ruídos articulares, evidência de interferência oclusal, facetas, mobilidade dentária, recessão gengival, abfração e dor dentária localizada. 
Resultados 


\section{RESULTADOS}

A análise dos dados evidenciou que a amostra de 43 pacientes era constituída de 31 mulheres (72,09\%) e de 12 homens $(27,91 \%)$, com idade média de 36,4 anos.

Os dados individuais referentes à magnitude da interferência oclusal (MIO), dor muscular (DM), dor articular (DA), presença de ruídos articulares $(R A)$, evidências de interferência oclusal $(E I O)$, facetas $(F A)$, mobilidade dentária $(M D)$, recessão gengival $(R G)$, abfração $(A B)$ e dor dentária localizada (DDL) estão descritos na tabela 15, no anexo 3.

O teste "t" de Student, representado na tabela 1, foi utilizado para comparar a magnitude da interferência oclusal com os sinais e sintomas de DTM e sinais clínicos de trauma oclusal. 
TABELA 1: Comparação das médias das magnitude da interferência oclusal $(\mathrm{mm})$ com sinais e sintomas de DTM e sinais clínicos de trauma oclusal.

\begin{tabular}{|c|c|c|c|c|c|c|c|c|}
\hline \multirow{2}{*}{ Variável } & \multicolumn{3}{|c|}{ Presença } & \multicolumn{3}{|c|}{ Ausência } & \multirow{2}{*}{$t$} & \multirow{2}{*}{$p$} \\
\hline & $n$ & média & $d p$ & $n$ & média & $d p$ & & \\
\hline$D M$ & 29 & 1,896 & 1,397 & 14 & 3,178 & 2,043 & 2,416 & $0,020^{*}$ \\
\hline$D A$ & 22 & 1,522 & 1,384 & 21 & 3,142 & 1,674 & 3,464 & $0,001^{*}$ \\
\hline$R A$ & 23 & 1,500 & 1,398 & 20 & 3,250 & 1,601 & 3,826 & $0,000^{*}$ \\
\hline EIO & 33 & 2,651 & 1,743 & 10 & 1,200 & 1,110 & 2,473 & $0,017^{*}$ \\
\hline$F A$ & 31 & 2,580 & 1,765 & 12 & 1,625 & 1,447 & 1,666 & 0,103 \\
\hline$M D$ & 14 & 2,821 & 1,551 & 29 & 2,068 & 1,771 & 1,356 & 0,182 \\
\hline$R G$ & 18 & 2,750 & 2,038 & 25 & 2,000 & 1,414 & 1,426 & 0,161 \\
\hline$A B$ & 19 & 2,684 & 1,872 & 24 & 2,020 & 1,570 & 1,263 & 0,213 \\
\hline$D D L$ & 7 & 3,142 & 1,573 & 36 & 2,152 & 1,723 & 1,408 & 0,166 \\
\hline
\end{tabular}

* diferença estatisticamente significativa.

DM - dor muscular, DA - dor articular, RA - presença de ruído articular, EIO - evidência de interferência oclusal, FA -

facetas, MD - mobilidade dentária, RG - recessão gengival, AB - abfração, DDL - dor dentária localizada.

O teste exato de Fisher foi utilizado para verificar: (1) a associação entre sexo e dor muscular, dor articular e presença de ruídos articulares; (2) a associação entre evidências de interferência oclusal e dor muscular, dor articular e presença de ruído articular e (3) a associação entre a magnitude da interferência oclusal e dor muscular, dor articular, presença de ruídos articulares, evidência de interferência oclusal, facetas, mobilidade dentária, recessão gengival, abfração e dor dentária localizada. Esses dados estão representados nas tabelas 2, $3,4,5,6,7,8,9,10,11,12,13$, e 14 . 
A tabela 2 mostra a associação entre a presença de dor muscular, dor articular e ruído articular nos dois sexos.

TABELA 2: Associação entre sexo e dor muscular, dor articular e ruído articular.

\begin{tabular}{|c|c|c|c|c|c|}
\hline \multirow{2}{*}{ Presença } & \multicolumn{2}{|c|}{ Feminino $(n=31)$} & \multicolumn{2}{|c|}{ Masculino $(n=12)$} & \multirow{2}{*}{$p$} \\
\hline & $n$ & $\%$ & $n$ & $\%$ & \\
\hline$D M$ & 24 & 77,42 & 5 & 41,67 & $0,035^{*}$ \\
\hline$D A$ & 20 & 64,52 & 2 & 16,67 & $0,006^{*}$ \\
\hline$R A$ & 19 & 61,29 & 4 & 33,33 & 0,172 \\
\hline
\end{tabular}

A tabela 3 mostra a associação entre evidências de interferência oclusal e dor muscular.

TABELA 3: Associação entre evidências de interferência oclusal e dor muscular.

\begin{tabular}{|c|c|c|c|c|c|}
\hline \multirow{2}{*}{$D M$} & \multicolumn{2}{|c|}{ Presença de EIO } & \multicolumn{2}{|c|}{ Ausência de EIO } & \multirow{2}{*}{ Tota } \\
\hline & $n$ & $\%$ & $n$ & $\%$ & \\
\hline Presença & 19 & 65,52 & 10 & 34,48 & 29 \\
\hline Ausência & 14 & 100,00 & 0 & 0,000 & 14 \\
\hline Total & 33 & 76,75 & 10 & 23,25 & 43 \\
\hline
\end{tabular}


A tabela 4 mostra a associação entre evidências de interferência oclusal e dor articular.

TABELA 4: Associação entre evidências de interferência oclusal e dor articular.

\begin{tabular}{cccccc}
\hline DA & \multicolumn{2}{c}{ Presença de EIO } & \multicolumn{2}{c}{ Ausência de EIO } & Total \\
\cline { 2 - 4 } & $\boldsymbol{n}$ & $\%$ & $\boldsymbol{n}$ & $\%$ & \\
Presença & 14 & 63,64 & 8 & 36,36 & 22 \\
Ausência & 19 & 90,48 & 2 & 9,52 & 21 \\
Total & 33 & 76,75 & 10 & 23,25 & 43 \\
$\begin{array}{l}\text { Teste de Fisher } \mathrm{p}=0,068 . \\
\text { DA - dor articular, ElO - evidência de interferência oclusal. }\end{array}$
\end{tabular}

A tabela 5 mostra a associação entre evidências de interferência oclusal e ruídos articulares.

TABELA 5: Associação entre evidências de interferência oclusal e ruídos articulares.

\begin{tabular}{cccccc}
\hline RA & \multicolumn{2}{c}{ Presença de EIO } & \multicolumn{2}{c}{ Ausência de EIO } & \multirow{2}{*}{ Total } \\
\cline { 2 - 4 } & $\boldsymbol{n}$ & $\%$ & $\boldsymbol{n}$ & $\%$ & \\
Presença & 15 & 65,22 & 8 & 34,78 & 23 \\
Ausência & 18 & 90,00 & 2 & 10,00 & 20 \\
Total & 33 & 76,75 & 10 & 23,25 & 43 \\
Teste de Fisher $\mathrm{p}=0,076$. & &
\end{tabular}


A tabela 6 mostra a associação entre a magnitude da interferência oclusal e dor muscular.

TABELA 6: Associação entre a magnitude da interferência oclusal e dor muscular.

\begin{tabular}{|c|c|c|c|c|c|}
\hline \multirow{2}{*}{ MIO } & \multicolumn{2}{|c|}{ Presença de DM } & \multicolumn{2}{|c|}{ Ausência de DM } & \multirow{2}{*}{ Total } \\
\hline & $n$ & $\%$ & $n$ & $\%$ & \\
\hline$\leq 2,5 \mathrm{~mm}$ & 20 & 80,00 & 5 & 20,00 & 25 \\
\hline$>2,5 \mathrm{~mm}$ & 9 & 50,00 & 9 & 50,00 & 18 \\
\hline Total & 29 & 67,44 & 14 & 32,56 & 43 \\
\hline
\end{tabular}

A tabela 7 mostra a associação entre a magnitude da interferência oclusal e dor articular.

TABELA 7: Associação entre a magnitude da interferência oclusal e dor articular.

\begin{tabular}{|c|c|c|c|c|c|}
\hline \multirow{2}{*}{ MIO } & \multicolumn{2}{|c|}{ Presença de DA } & \multicolumn{2}{|c|}{ Ausência de DA } & \multirow{2}{*}{ Total } \\
\hline & $n$ & $\%$ & $n$ & $\%$ & \\
\hline$\leq 2,5 \mathrm{~mm}$ & 17 & 68,00 & 8 & 32,00 & 25 \\
\hline$>2,5 \mathrm{~mm}$ & 5 & 27,78 & 13 & 72,22 & 18 \\
\hline Total & 22 & 51,16 & 21 & 48,84 & 43 \\
\hline
\end{tabular}


A tabela 8 mostra a associação entre a magnitude da interferência oclusal e ruído articular.

TABELA 8: Associação entre a magnitude da interferência oclusal e ruído articular.

\begin{tabular}{|c|c|c|c|c|c|}
\hline \multirow{2}{*}{ MIO } & \multicolumn{2}{|c|}{ Presença de RA } & \multicolumn{2}{|c|}{ Ausência de RA } & \multirow{2}{*}{ Total } \\
\hline & $n$ & $\%$ & $n$ & $\%$ & \\
\hline$\leq 2,5 \mathrm{~mm}$ & 18 & 72,00 & 7 & 28,00 & 25 \\
\hline$>2,5 \mathrm{~mm}$ & 5 & 27,78 & 13 & 72,22 & 18 \\
\hline Total & 23 & 53,49 & 20 & 46,51 & 43 \\
\hline
\end{tabular}

A tabela 9 mostra a associação entre a magnitude da interferência oclusal e evidências de interferência oclusal.

TABELA 9: Associação entre a magnitude da interferência oclusal e evidências de interferência oclusal.

\begin{tabular}{|c|c|c|c|c|c|}
\hline \multirow{2}{*}{ MIO } & \multicolumn{2}{|c|}{ Presença de EIO } & \multicolumn{2}{|c|}{ Ausência de EIO } & \multirow{2}{*}{ Tota } \\
\hline & $n$ & $\%$ & $n$ & $\%$ & \\
\hline$\leq 2,5 \mathrm{~mm}$ & 9 & 36,00 & 16 & 64,00 & 25 \\
\hline$>2,5 \mathrm{~mm}$ & 1 & 5,56 & 17 & 94,44 & 18 \\
\hline Total & 10 & 23,25 & 33 & 76,75 & 43 \\
\hline
\end{tabular}

Teste de Fisher $p=0,028^{*}$

MIO - magnitude da interferência oclusal, EIO - evidências de interferência oclusal. 
A tabela 10 mostra a associação entre a magnitude da interferência oclusal e facetas.

TABELA 10: Assoc iação entre a magnitude da interferência oclusal e facetas.

\begin{tabular}{|c|c|c|c|c|c|}
\hline \multirow{2}{*}{ MIO } & \multicolumn{2}{|c|}{ Presença de FA } & \multicolumn{2}{|c|}{ Ausência de FA } & \multirow{2}{*}{ Total } \\
\hline & $n$ & $\%$ & $n$ & $\%$ & \\
\hline$\leq 2,5 \mathrm{~mm}$ & 15 & 60,00 & 10 & 40,00 & 25 \\
\hline$>2,5 \mathrm{~mm}$ & 16 & 88,89 & 2 & 11,11 & 18 \\
\hline Total & 31 & 72,09 & 12 & 27,91 & 43 \\
\hline
\end{tabular}

A tabela 11 mostra a associação entre a magnitude da interferência oclusal e mobilidade dentária.

TABELA 11: Associação entre a magnitude da interferência oclusal e mobilidade dentária.

\begin{tabular}{|c|c|c|c|c|c|}
\hline \multirow{2}{*}{$M I O$} & \multicolumn{2}{|c|}{ Presença de MD } & \multicolumn{2}{|c|}{ Ausência de MD } & \multirow{2}{*}{ Total } \\
\hline & $n$ & $\%$ & $n$ & $\%$ & \\
\hline$\leq 2,5 \mathrm{~mm}$ & 5 & 20,00 & 20 & 80,00 & 25 \\
\hline$>2,5 \mathrm{~mm}$ & 9 & 50,00 & 9 & 50,00 & 18 \\
\hline Total & 14 & 67,45 & 29 & 32,55 & 43 \\
\hline
\end{tabular}


A tabela 12 mostra a associação entre a magnitude da interferência oclusal e recessão gengival.

TABELA 12: Associação entre a magnitude da interferência oclusal e recessão gengival.

\begin{tabular}{|c|c|c|c|c|c|}
\hline \multirow{2}{*}{ MIO } & \multicolumn{2}{|c|}{ Presença de RG } & \multicolumn{2}{|c|}{ Ausência de RG } & \multirow{2}{*}{ Tota } \\
\hline & $n$ & $\%$ & $n$ & $\%$ & \\
\hline$\leq 2,5 \mathrm{~mm}$ & 8 & 32,00 & 17 & 68,00 & 25 \\
\hline$>2,5 \mathrm{~mm}$ & 10 & 55,56 & 8 & 44,44 & 18 \\
\hline Total & 18 & 41,86 & 25 & 52,14 & 43 \\
\hline
\end{tabular}

A tabela 13 mostra a associação entre a magnitude da interferência oclusal e abfração.

TABELA 13: Associação entre a magnitude da interferência oclusal e abfração.

\begin{tabular}{|c|c|c|c|c|c|}
\hline \multirow{2}{*}{ MIO } & \multicolumn{2}{|c|}{ Presença de AB } & \multicolumn{2}{|c|}{ Ausência de $A B$} & \multirow{2}{*}{ Total } \\
\hline & $n$ & $\%$ & $n$ & $\%$ & \\
\hline$\leq 2,5 \mathrm{~mm}$ & 9 & 36,00 & 16 & 64,00 & 25 \\
\hline$>2,5 \mathrm{~mm}$ & 10 & 55,56 & 8 & 44,44 & 18 \\
\hline Total & 19 & 44,19 & 24 & 55,81 & 43 \\
\hline
\end{tabular}

Teste de Fisher $p=0,230$

MIO - magnitude da interferência oclusal, AB - abfração. 
A tabela 14 mostra a associação entre a magnitude da interferência oclusal e dor dentária localizada.

\begin{tabular}{|c|c|c|c|c|c|}
\hline \multirow{2}{*}{ MIO } & \multicolumn{2}{|c|}{ Presença de $D D L$} & \multicolumn{2}{|c|}{ Ausência de DDI } & \multirow{2}{*}{ Total } \\
\hline & $n$ & $\%$ & $n$ & $\%$ & \\
\hline$\leq 2,5 \mathrm{~mm}$ & 2 & 8,00 & 23 & 92,00 & 25 \\
\hline$>2,5 \mathrm{~mm}$ & 5 & 27,78 & 13 & 72,22 & 18 \\
\hline Total & 7 & 16,28 & 36 & 83,72 & 43 \\
\hline
\end{tabular}

MIO - magnitude da interferência oclusal, DDL - dor dentária localizada. 


\section{DISCUSSÃO}

Segundo OKESON ${ }^{52}$, as DTMs são um conjunto de sinais e sintomas relativos às desordens da ATM, os quais nem sempre aparecem restritos somente na ATM. Como os sinais e sintomas característicos de DTM afetam as funções do Sistema Estomatognático, é preciso que eles sejam estudados tanto nas ATMs quanto nos músculos e nos dentes.

Para CONTI ${ }^{14}$, uma interferência oclusal é uma situação de contato dentário que interfere de alguma maneira na função ou parafunção do sistema estomatognático, podendo estar associada, de alguma maneira, com a etiologia multifatorial das DTMs ${ }^{33}$. Existem, na literatura, várias teorias a respeito do efeito das interferências oclusais na etiologia das DTMs. Vários autores, através de estudos epidemiológicos ${ }^{23,35,40,58,68}$, estudos experimentais em humanos ${ }^{19,46,62,66} \mathrm{e}$ em animais ${ }^{07,28,54,64}$ verificaram o papel das interferências oclusais na etiologia multifatorial das DTMs. Esses estudos verificaram se as interferências oclusais poderiam causar dor muscular, aumento da atividade eletromiográfica, dor articular, ruído articular, alterações ósseas, facetas de desgaste, mobilidade dentária, recessão gengival, abfração, dor dentária localizada e alterações pulpares.

Alguns estudos preliminares ${ }^{35}, 48,52$ classificaram dor muscular, dor articular, ruído articular, facetas de desgaste, mobilidade dentária, recessão gengival, abfração e dor dentária localizada como sinais e sintomas de 
DTM. Estudos mais recentes fazem uma divisão entre sinais e sintomas de DTM e evidências de interferência oclusal ou sinais clínicos de trauma oclusal. DAWSON ${ }^{17}$, CLARK $^{12}$, PULLINGER ${ }^{58}$ classificam dor muscular, dor articular e ruído articular como sinais e sintomas de DTM; e facetas de desgaste, mobilidade dentária, recessão gengival, abfração e dor dentária localizada como evidências de interferência oclusal ou sinais clínicos de trauma oclusal. Nosso estudo classificou os sinais clínicos de trauma oclusal como sendo evidências de interferência oclusal.

Alguns estudos ${ }^{18,19,20,23,27,29,40,41,46,50,65,66,68,75}$ sugerem que as interferências oclusais têm um papel limitado na sintomatologia das DTMs. Outros $^{16,17,33,42,64,69}$ sugerem que existe uma associação entre interferências oclusais e as DTMs. Existem, ainda, estudos ${ }^{48,56,58}$ que indicam que as DTMs podem causar interferências oclusais. Os resultados do nosso estudo mostraram que as evidências de interferência oclusal estão presentes nos pacientes com e sem sinais e sintomas de DTM. Esses dados sugerem que as interferências oclusais não são fatores etiológicos das DTMs, conforme pode ser observado nas tabelas 3, 4,5.

A tabela 3 , referente àpresença e ausência de dor muscular e evidências de interferência oclusal mostra que, no grupo com dor muscular, o número de pacientes com evidências de interferência oclusal $(65,52 \%)$ foi significativamente maior do que o número de pacientes sem evidência de interferência oclusal $(34,48 \%),(p=0,017)$. No grupo sem dor muscular, todos os pacientes apresentaram evidências de interferência oclusal (100,00\%). Esses dados estão de acordo com os resultados de alguns estudos ${ }^{12,14,25,36,47}$ que sugerem, que 
apesar das interferências oclusais ocorrerem simultaneamente com dor muscular, não existe relação entre dor muscular e interferência oclusal, já que estas também ocorrem em pacientes assintomáticos. Nossos resultados discordam dos resultados de BELL et $\mathrm{al}^{06}$ os quais acreditam que, em pacientes com história de DTM, as interferências oclusais podem desencadear dor muscular e outros sintomas de DTM. NISHIDE ${ }^{51}$, WATANABE ${ }^{73}$ e KVINNSLAND ${ }^{42}$ afirmam, ainda, que as interferências oclusais podem provocar dor muscular tanto em pacientes sintomáticos quanto assintomáticos.

A tabela 4 mostra que quando analisadas a presença e ausência de dor articular e evidências de interferência oclusal, não houve diferença estatisticamente significativa entre as variáveis estudadas $(p=0.068)$. A tabela também mostra que, no grupo com dor articular, 63,4\% dos pacientes apresentaram evidências de interferências oclusais e que no grupo sem dor articular, 90,48\% dos pacientes apresentaram evidências de interferências oclusais. Esses dados sugerem que a presença de evidências de interferências oclusais não é um fator desencadeante de dor articular. Nossos resultados estão de acordo com os resultados de alguns estudos ${ }^{14,25,35,58,65}$ que afirmaram que não existem alterações oclusais que possam, separadamente, indicar o desenvolvimento de dor articular, entre elas as interferências oclusais. Entretanto esses dados discordam dos estudos de EGERMARK-ERIKSSON ${ }^{23}$ e INGERVALL ${ }^{33}$ que afirmaram ter encontrado associação entre interferências oclusais e dor articular. 
A tabela 5, referente à presença e ausência de ruídos articulares e evidências de interferência oclusal, mostra que no grupo com ruído articular, o número de pacientes que apresentaram evidências de interferências oclusais $(65,22 \%)$ foi maior que o número de pacientes sem evidências de interferências oclusais $(34,78 \%)$, embora não tenha sido estatisticamente significativo, $(p=0,076)$. No grupo sem ruídos articulares, $90,00 \%$ dos pacientes apresentaram evidências de interferências oclusais. Esses dados estão de acordo com alguns estudos ${ }^{14,25,35,58,65,75}$ que acreditam que as evidências de interferências oclusais não estão associadas ao desenvolvimento de ruídos articulares. Nossos resultados não concordam com os estudos de INGERVALL ${ }^{33}$ e SELIGMAN; PULLINGER ${ }^{67}$ que associaram evidências de interferências oclusais com a presença de ruídos articulares, e indicaram o ajuste oclusal para estes casos, sempre que possível.

Conforme foi demonstrado na revisão da literatura, foi desenvolvida uma série de estudos relacionados à magnitude das interferências oclusais $^{19,46,62,66}$. No entanto nenhum deles conseguiu esclarecer se a magnitude das interferências oclusais atua de maneira diferente na etiologia das DTMs. Para esclarecer essa dúvida e determinar o verdadeiro papel das interferências oclusais na etiologia das DTMs, é preciso conhecer as interferências oclusais e quantificar sua magnitude.

A maioria dos trabalhos ${ }^{13}, 18,26,27,32,33,34,35,54,55$ sobre a magnitude das interferências oclusais verificou a quantidade de deslize da posição 
de $\mathrm{RC}$ para $\mathrm{MIH}$, no sentido horizontal. Os estudos ${ }^{02,23,41,58,59,65,66,73,75}$, que quantificaram a magnitude das interferências oclusais no sentido horizontal, observaram que a magnitude das interferências não era superior a $3 \mathrm{~mm}$ durante o deslize da posição de RC para MIH. Sugeriram, também, que interferências com magnitude de até $3 \mathrm{~mm}$ podem produzir danos localizados nos dentes ou nos músculos, mas não são suficientes para desenvolver DTMs. GEERING ${ }^{27}$; BUTDZJORGENSEN $^{09}$ verificaram que para as magnitudes inferiores a $3 \mathrm{~mm}$ o desenvolvimento de DTM depende do tipo de interferência e da predisposição de cada indivíduo. MAGNUSSUM ${ }^{46}$ e SELIGMAN; PULLINGER; SOLBERG ${ }^{58}$ afirmaram que o relacionamento entre a magnitude das interferências oclusais e sinais e sintomas de DTM é complexo, uma vez que as DTMs induzem a uma adaptação fisiológica do Sistema Estomatognático, produzindo interferências oclusais.

Poucos estudos ${ }^{06,15,32,62}$ verificaram a magnitude das interferências oclusais no sentido vertical. Nesses casos, a quantificação da magnitude das interferências se dava na região posterior, através da instalação de interferências experimentais de dimensões previamente determinadas. Os estudos que quantificaram a magnitude das interferências oclusais no sentido vertical, utilizaram interferências oclusais experimentais de até $4 \mathrm{~mm}$ na região posterior, por um período máximo de quatro semanas. Através destes estudos foi possível observar que, nos pacientes com predisposição de desenvolvimento de DTM, quanto maior a magnitude e o tempo de permanência da interferência, maior a capacidade de desenvolver sinais e sintomas de DTM e evidências de interferência oclusal ${ }^{\beta 3}$. 
BELL et al. ${ }^{06}$ verificaram que os pacientes que não tinham predisposição de desenvolvimento de DTM não desenvolveram sinais e sintomas de DTM e evidências de interferência oclusal, independente da magnitude e do tempo de duração da interferência. Isso pode ser explicado pelo fato de o Sistema Estomatognático apresentar, após uma semana, uma alta capacidade adaptativa ${ }^{36}$. Por outro lado MCNAMARA; SELIGMAN; OKESON ${ }^{48}$ acreditam que as discrepâncias verticais entre $\mathrm{RC}$ e $\mathrm{MIH}$, maiores que $2 \mathrm{~mm}$, são conseqüência e não causa de DTM.

Nosso estudo quantificou, através de uma nova metodologia, a magnitude de interferências oclusais reais no sentido vertical, aferidas na região anterior. A mensuração da magnitude da interferência oclusal foi realizada na borda incisal do incisivo superior, na face vestibular do incisivo inferior, com a mandíbula nas posições de MIH e de contato interferente. A diferença, em milímetros, dessa posição determinou a magnitude da interferência. Essa metodologia é uma adaptação da metodologia utilizada nos estudos de $A G E R B E R G^{01}$ e BELL ${ }^{06}$, os quais utilizaram a região dos incisivos para mensurar as interferências oclusais no sentido horizontal. Sua utilização se deve àfacilidade e confiabilidade do registro da magnitude da interferência oclusal, que não seria possível se a mensuração fosse realizada na região posterior. Acreditamos que as grandes magnitudes de interferências oclusais encontradas em nosso estudo devem-se ao fato de a mensuração ter sido realizada na região anterior. No entanto, estes dados podem ser comparados aos estudos tradicionais ${ }^{05}, 18,26,27,32,48,66$ realizados com 
interferências oclusais experimentais, já que acreditamos que grandes magnitudes encontradas na região anterior podem ser transferidas proporcionalmente para a região posterior.

Nossos resultados mostraram que não houve uma relação entre a magnitude das interferências oclusais e sinais e sintomas de DTM, conforme pode ser observado na tabela 1 . Os pacientes sem sinais e sintomas de DTM apresentaram magnitude de interferências oclusais maiores que o grupo com sinais e sintomas de DTM, tabela 1. Os dados referentes à magnitude das interferências oclusais menores ou iguais a $2,5 \mathrm{~mm}$ e interferências maiores que $2,5 \mathrm{~mm}$, bem como os sinais e sintomas de DTM, podem ser observados nas tabelas 6,7 e 8 , e mostram que a magnitude das interferências oclusais não pode ser associada com sinais e sintomas de DTM. Na tabela 6, quando analisadas a magnitude da interferência oclusal e a presença e a ausência de dor muscular, verifica-se que não houve diferença estatisticamente significativa $(p=0,052)$ entre as variáveis estudadas. Também é possível verificar que o número de pacientes com presença e ausência de dor muscular foi o mesmo para as interferências oclusais maiores que 2,5mm. Isso sugere que as interferências oclusais dessa magnitude não causam sintomatologia dolorosa muscular. Esses resultados assemelham-se com aqueles estudados por SHAERER ${ }^{66}$; FUNAKOSH²; INGERVALL ${ }^{33}$, que afirmaram não haver associação estatisticamente significativa entre história de dor muscular e interferências oclusais. No entanto, diferem do trabalho de WESTLING ${ }^{75}$, que 
acredita na associação entre interferências oclusais unilaterais em RC com a presença de dor muscular.

A tabela 7 mostra que, quando analisadas a magnitude da interferência oclusal e a presença ou ausência de dor articular, houve diferença estatisticamente significativa $(p=0.013)$ entre as variáveis estudadas. $O$ grupo sem dor articular apresentou interferências oclusais maiores que o grupo com dor articular. Também é possível verificar que a maioria dos pacientes sem dor articular $(72,22 \%)$, apresentaram magnitude de interferência oclusal maior que $2,5 \mathrm{~mm}$. Isso sugere que a magnitude da interferência oclusal não é um fator etiológico para o aparecimento de dor nas ATMs. Esses dados estão de acordo com os achados de RUBEN $^{64}$ e DE BOEVER ${ }^{19}$, os quais mostraram que a magnitude das interferências oclusais pareceu não influenciar na severidade da dor articular. No entanto não concordam com os estudos de SELIGMAN e PULLINGER ${ }^{67}$, WESTLING ${ }^{75}$ que observaram que a magnitude das interferências oclusais podem desenvolver dor articular.

A tabela 8 mostra que, quando analisadas a magnitude da interferência oclusal e presença e ausência de ruído articular, houve diferença estatisticamente significativa $(p=0,005)$ entre as variáveis estudadas. $O$ grupo sem ruído articular apresentou interferências oclusais maiores que o grupo com ruído articular. Também é possível verificar que a maioria dos pacientes sem ruído articular (72,22\%) apresentaram magnitude de interferência oclusal maior que 2,5mm. Esses dados estão de acordo com FUNAKOSH²6; INGERVALL ${ }^{33}$; 
$R U N G E^{65}$, que não encontraram associação estatisticamente significativa entre a presença ou ausência de ruídos articulares e magnitude das interferências oclusais. Entretanto, contradizem os estudos de SELIGMAN e PULLINGER ${ }^{67}$, WESTLING ${ }^{75}$ que observaram a presença de ruídos articulares em pacientes com interferências oclusais em RC.

A tabela 9 , referente à magnitude da interferência oclusal $\mathrm{e}$ presença e ausência de evidências de interferência oclusal, mostra que o grupo (94,44\%) sem evidências de interferência oclusal apresentou magnitude de interferências oclusais significativamente maiores que o grupo com evidências de interferência oclusal $(p=0,028)$. A tabela mostra que houve diferença estatisticamente entre todas as variáveis estudadas. Esses dados sugerem que grandes magnitudes de interferências oclusais não necessariamente se apresentam como as evidencias de interferência oclusal. Esses resultados estão de acordo com os estudos de KARLSSON ${ }^{36}$; $\mathrm{JOHN}^{34}$, que relataram não haver associação entre a presença de interferências e a presença de alguns sinais clínicos de trauma oclusal. Estes autores acreditam na adaptação fisiológica da mandíbula para uma nova posição com a finalidade de se evitar o trauma oclusal. Já FUNAKOSH²6; BUDTZJORGENSEN ${ }^{09}$; IKEDA ${ }^{32}$ afirmam que a maioria dos dentes submetido ao trauma oclusal, através de um contato interferente, mostram alguma evidência de interferência oclusal. Estes autores relatam, ainda, que os dentes recuperam sua condição normal após o ajuste da interferência oclusal. 
A tabela 10 mostra que, quando analisadas a magnitude da interferência oclusal e presença e ausência de facetas, houve diferença estatisticamente significativa entre as variáveis estudadas $(p=0,046)$. $O$ teste revelou que as facetas estavam presentes em $88,89 \%$ dos pacientes com magnitude de interferência oclusal maior que $2,5 \mathrm{~mm}$, e em $60,00 \%$ dos pacientes com magnitude de interferência oclusal menor ou igual a 2,5mm. Esses dados sugerem que, apesar de estarem relacionadas com a presença de facetas, a diferença na magnitude das interferências oclusais não constitui fator etiológico para o desenvolvimento de facetas de desgaste. Nossos resultados estão de acordo com os resultados de alguns estudos ${ }^{23,34,39,65}$ que afirmam que um aumento significativo das facetas de desgaste não ocorre com o aumento da magnitude das interferências oclusais. Eles observaram que as facetas de desgaste estavam presentes tanto em pacientes com interferências oclusais quanto em pacientes sem interferências oclusais. No entanto, nossos resultados discordam de outros estudos ${ }^{09,20}$ que relatam o aumento de facetas de desgaste em dentes submetidos a interferências oclusais experimentais. SELIGMAN; PULLINGER ${ }^{67}$ sugerem que a presença de facetas de desgaste ocorre com a finalidade de reduzir a prevalência de contatos dentários interferentes.

A tabela 11, referente àmagnitude da interferência oclusal e presença e ausência de mobilidade dentária, mostra que não houve diferença estatisticamente significativa entre as variáveis estudadas $(p=0,052)$. Os dados evidenciam que no grupo com magnitude de interferências oclusais maiores que 2,5mm, a presença ou ausência de mobilidade dentária apresentourse igualmente 
distribuída entre os grupos (50,00\%). Esses dados concordam com os resultados encontrados por SVANBERG; LINDHÉ ${ }^{72}$ e BUDTZ-JORGENSEN ${ }^{09}$ que encontraram, inicialmente, uma grande mobilidade dentária causada por interferências oclusais, as quais foram diminuindo, com o passar do tempo, pela adaptação do periodonto. Esses estudos podem explicar os nossos resultados, já que as interferências oclusais estudadas apresentavam-se presentes na boca naturalmente, oferecendo tempo suficiente para que ocorresse a adaptação fisiológica do periodonto.

A tabela 12 mostra que, quando analisadas a magnitude da interferência oclusal e a presença ou ausência de recessão gengival, não houve diferença estatisticamente significativa entre as variáveis estudadas $(p=0,209)$. Os dados mostram que houve uma distribuição uniforme dos pacientes com e sem recessão gengival no grupo com magnitude de interferência oclusal maior que 2,5mm. Isso sugere que não há nenhuma associação entre a magnitude da interferência oclusal e o desenvolvimento de recessão gengival. Nossos resultados estão de acordo com os estudos de SVANBERG; LINDHÉ ${ }^{72} ; \mathrm{KHAN}^{39}$, que afirmaram não haver relação entre a presença de interferências oclusais e recessão gengival. Eles observaram que o desenvolvimento de recessão gengival está associado ao trauma causado pela escovação, durante os procedimentos de higiene bucal, ou com perdas ósseas relacionadas à doença periodontal. Entretanto, alguns estudos ${ }^{39}$, ${ }^{43}$ afirmam que pode ocorrer recessão gengival, causada por interferência oclusal, no dente do contato interferente. 
A tabela 13, referente à associação entre magnitude da interferência oclusal e presença e ausência de abfração, mostrou que não houve diferença estatisticamente significativa entre as variáveis estudadas $(p=0,230)$. Os dados mostram que houve uma distribuição uniforme dos pacientes $(55,56 \%)$ com abfração no grupo com magnitude de interferência oclusal maior que 2,5mm. Isso sugere que não há nenhuma associação entre a magnitude da interferência oclusal e o desenvolvimento de abfração. Nossos resultados estão de acordo com alguns estudos $^{44,39}$ que observaram que a presença de abfração foi comum em pacientes com e sem a presença de interferências. Embora não seja possível mensurar a contribuição das interferências oclusais na formação direta das abfrações, PIOTROWSK ${ }^{3}$ relata que a possibilidade de associação entre a magnitude das

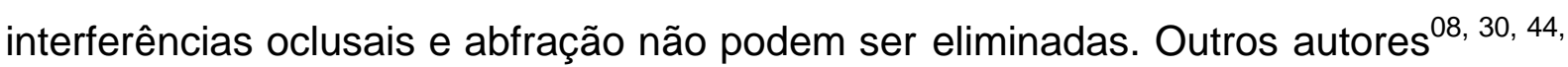
${ }^{53}$, que discordam dos nossos resultados, encontraram que as abfrações estão associadas com a direção, freqüência e magnitude das interferências oclusais.

A tabela 14 mostra que, quando analisadas a magnitude da interferência oclusal e presença e ausência de dor dentária localizada, não houve diferença estatisticamente significativa entre as variáveis estudadas $(p=0,110)$. Os dados mostram que no grupo com magnitude de interferência oclusal maior que 2,5mm, apenas $27,78 \%$ dos pacientes apresentaram dor dentária localizada. Nossos resultados estão de acordo com o estudo de $\mathrm{CLARK}^{12}$, que afirmou que a dor dentária causada por diferentes magnitudes de interferências oclusais é transitória. Ele afirma que dentes sob trauma oclusal tendem a mudar de posição com a 
finalidade de se evitar o trauma oclusal. Entretanto, nossos resultados diferem de outros estudos ${ }^{26,32,47}$, que observaram dor dentária localizada no dente sob trauma oclusal. Os autores relatam, ainda, que a sensibilidade desaparecerá assim que o contato interferente for ajustado.

Embora nosso estudo não tivesse o objetivo de comparar qualitativa e quantitativamente as áreas de desgaste e a magnitude das interferências oclusais, observamos desgastes severos e generalizados em dentes de pacientes com magnitudes de interferência oclusal maior que $5 \mathrm{~mm}$. No entanto os pacientes que apresentavam esses fatores não apresentavam sinais e sintomas de DTM. Esses dados estão de acordo com o estudo de JOHN et al. ${ }^{34}$ que não encontraram associação entre desgastes generalizados e sinais e sintomas de DTM, já que os sinais de desgaste estavam assimetricamente distribuídos nos grupos sintomático e assintomático.

Como observado neste e em outros estudos ${ }^{06,12,14}$, uma interferência oclusal só deve ser tratada se alguma evidência de dano ao Sistema Estomatognático estiver presente. Nossos resultados estão de acordo com BELL et al. ${ }^{06}$, que acreditam não ser necessário qualquer tipo de intervenção para eliminar as interferências oclusais em indivíduos assintomáticos, já que a maioria dos indivíduos adapta-se àpresença de grandes magnitudes de interferências oclusais. ASAZUMA et al. ${ }^{02}$ acreditam que, até o momento, somente uma avaliação criteriosa das interferências oclusais e dos danos causados no Sistema Estomatognático podem oferecer ao clínico informações seguras sobre a real necessidade de eliminação das 
interferências. Nosso estudo sugere a revisão da escolha por tratamentos irreversíveis, já que as interferências oclusais não parecem causar tantos danos ao Sistema Estomatognático. Os resultados deste estudo concordam com o resultado de alguns estudos ${ }^{18,19}, 20,23,27,29,40,41,46,50,65,66,67,68,75$ que mostram que a magnitude das interferências oclusais tem um papel limitado dentro da etiologia multifatorial das DTMs. 
Conclusões 


\section{CONCLUSÃO}

A partir da metodologia aplicada e após a análise dos resultados, podemos concluir que:

Não houve associação entre a magnitude das interferências oclusais e sinais clínicos de trauma oclusal e sinais e sintomas de Desordens Temporomandibulares, sugerindo que a magnitude das interferências oclusais não está relacionada com o desenvolvimento de sinais clínicos de trauma oclusal e sinais e sintomas de Desordens Temporomandibulares. 


\section{REFERÊNCIAS BIBLIOGRÁFICAS*}

01. AGERBERG, G.; SANDSTROW, R. Frequency of occlusal interferences: a clinical study in teenagers and young adults. J. prosthet. Dent., v.59, n.2, p.212-17, Feb. 1988.

02. ASAZUMA, Y. et al. Changes in gnathosonic and tooth contact characteristics induced by experimental occlusal interferences created using a full-cast double crown. J. oral Rehab., v.22, n. 3, p. 203-11, Mar. 1995.

03. AUSTIN, D.G.; PERTES, R.A. Examination of the TMD patient. In: PERTES, R.A.; GROSS, S.G. Clinical management of temporomandibular disorders and orofacial pain. Chicago, Quintessence, 1995. p.123-60.

04. BABA, K. et al. Influence of experimental occlusal discrepancy on masticatory muscle activity during clenching. J. oral Rehab., v.23, n.11, p.55-60, Nov. 1996.

05. BAKKE, M; MOLLER, E. Distortion of maximal elevator activity by unilateral premature tooth contact. Scand. J. dent. Res., v.88, n.2, p.67-75, Feb. 1980.

06. BELL, Y.L. et al. Effect of artificial occlusal interferences depends on previous experience of temporomandibular disorders. Acta odontol. Scand., v. 60, n.1, p. 219-22, Aug. 2002.

\footnotetext{
*Normas recomendadas para uso no âmbito da Universidade de São Paulo, com base no documento "Referências Bibliográficas: exemplos", emanado do conselho supervisor do sistema integrado de bibliotecas da USP, em reunião de 1990.
} 
07. BOX, H.K. Experimental traumatogenic occlusion in sheep. Oral Health., v.25, n.3, p.9-15, Mar. 1935.

08. BRADY, J.M.; WOODY, R.D. Scanning microscopy of cervical erosion. J. Amer. dent. Ass., v. 94, n.1, p.726-9, Feb. 1977.

09. BUDTZ-JORGENSEN, E. A 3-month study in monkeys of occlusal dysfunction and stress. Scand. J. dent. Res., v.88, n.3, p.171-80, June 1980.

10. BURKE, F.J.T.; WHITEHEAD, S.A.; MCCAUGHEY, A.D. Comtemporary. concepts in the pathogenesis of the class $\mathrm{V}$ non-carious lesion. Dent. Update., v. 22, n.1, p.28-32, Feb. 1995.

11. CLARK, G.T. Interocclusal appliance therapy. In: MOHL, N.D. et al. Textbook of occlusion. Chicago, Quintessence, Publishing Co., 1988. p.271-284.

12. CLARK, G.T. et al. Sixty-eight years of experimental occlusal interference studies: what have we learned? J. prosthet. Dent., v.82, n.6, p.704-13, Dec. 1999.

13. CLARK, J.R. et al. Functional occlusion: I. a review. J. Orthodont., v.28, n. 1, p. 76-81, Mar. 2001.

14. CONTI, P.C.R. et al. A cross-sectional study of prevalence and etiology of signs and symptoms of temporomandibular disorders in high school and university students. J. Orofac. Pain., v.10, n.3, p. 254-62, Summer 1980.

15. CHRISTENSEN, L.V.; RASSOULI, M.N. Experimental occlusal interferences. part IV. mandibular rotations induced by a pliable interference. J. oral Rehab., v.22, n. 11, p. 835-44, Nov. 1995. 
16. CHRISTENSEN, L.V.; RASSOULI, N.M. Experimental occlusal interferences. part II. masseteric EMG responses to an intercuspal interference. J.Oral Rehab., v.22, n.7, p.521-31, July. 1995.

17. DAWSON, P.E. Evaluation diagnosis and treatment of occlusal problem. 1.ed. St Louis, CV Mosby, 1974.

18. DE BOEVER, J. Experimental oclusal balancing-contact interference and muscle activity. an electromyographic study with permanently applied electrodes. Parodontologie. v.23, n.2, p.49-56, June 1969.

19. DE BOEVER, J.O.; ADRIAENS, P.A. Occlusal relationship in patients with paindysfunction symptoms in temporomandibular joints. J. oral Rehab. v.10, n. 1, p. 1-7, Jan. 1983.

20. DROUKAS, B.; LINDÉE, C.; CARLSSON, G.E. Relationship between occlusal factors and signs and symptoms of mandibular dysfunction. a clinical study of 48 dental students. Acta odont. Scand., v. 42, n.5, p. 277-83, May 1984.

21. DUPAS, P.H. et al. Centric relation and programming semiadjustable articulators with the universal jig. Part II: Experiments. J. prosthet. Dent., v. 65, n.1, p.86-9, Jan. 1991.

22. DWORKIN, S.F.; LERESHE, L. Research diagnostic criteria for temporomandibular disorders: review, criteria, examinations and specifications, critic. J. craniomandibular dis. Fac. oral pain., 1992; 6: 301-55. 
23. EGERMARK- ERIKSSON, I.; CARLSSON, G.E.; MAGNUSON, T. A long-term epidemiologic study of the relationship between occlusal factors and mandibular dysfunction in children and adolescents. J. dent. Res., v.66, n. 1, p. 67-71, Jan. 1987.

24. EGERMARK, I.; RONNERMAN, A. Temporomandibular disorders in the active phase of orthodontic treatment. J. oral Rehab., v. 22, n. 8, p.613-8, Aug. 1995.

25. FUJII, T. The relationship between the occlusal interference side and the symptomatic side in temporomandibular disorders. J. oral Rehab., v. 30, n.3, p.295-300, Mar. 2003.

26. FUNAKOSHI, M.; FUJITA, N.; TAKEHAN, S. Relations between occlusal interference and jaw muscle activities in response to changes in head position. J. dent. Res., v.55, n.4, p.684-90, July/Aug. 1976.

27. GEERING,A.H. Occlusal interference and funcional disturbances of masticatory system. J. clin Periodont., v.1, n.2, p.112-9, 1974.

28. GOTTLIEB, B.; ORBAN, B. Tissue changes in experimental traumatic occlusion, with special reference to age and constitution. J. dent. Res., v.11, n.2, p.505-10, July. 1931.

29. GRAF, H.; ZANDER, H.A. Tooth contact patterns in mastication. J. prosthet. Dent., v.13, n.10, p.1055-66,Oct. 1963.

30. GRIPPO, J.O. Abfractions: a new classification of hard tissue lesions of teeth. J. esthet. Dent., v. 132, n.12, p.1694-701, Dec. 2001. 
31. HORNING, G.M.; COHEN, M.E.; NEILS, T.A. Buccal alveolar exostoses: prevalence, characteristics, and evidence for buttressing bone formation. J. Periodontol., v. 71, n.6, p.1032-42, June. 2000.

32. IKEDA, T. et al. The effect of light premature occlusal contacts on tooth pain treshold in humans. J. oral Rehab., v.25, n. 8, p. 589-95, Aug. 1998.

33. INGERVALL, B.; MOHLIN, B.; THILANDER, B. Prevalence of symptomas of functional disturbances of the masticatory system in swedish men. J. oral Rehab. v.7, n. 3, p. 185-197, May. 1995.

34. JOHN, M.P. et al. No association between incisal tooth wear and temporomandibular disorders. J. prosthet. Dent., v.87, n.2, p.197-203, Feb. 2002.

35. KAHN, J. et al. Prevalence of dental occlusal variables and intraarticular temporomandibular disorders: molar relationship, lateral guidance, and nonworking side contacts. J. prosthet. Dent., v.82, n.4, p.410-5, Oct. 1999

36. KARLSON, S.; CHO, S.A.; CARLSSON, G.E. Changes in mandibular masticatory movements after insertion of nonworking-side interference. J. craniomandibular Disord., v.13, n.4 , p.177-83, Mar. 1992.

37. KERSTEIN, R.B.; WILKERSON, D. Location the centric relation prematurity with computerized occlusal analysis system. Compend. cont. educ. Dent., v.22, n. 6, p. 525-32, June 2001.

38. KHAN, F. et al. Dental cervical lesions associated with occlusal erosion and attrition. Aust. dent. J., v. 44, n.3, p.176-186, May. 1999. 
39. KHAN, F.;YOUNG, W.G.; DALEY, T.J. Dental erosion and bruxism: a tooth wear. Aust. dent. J., v. 3, n.1, p.14-9, Jan. 1991.

40. KIRVESKARI, P.; ALANEN, P.; JANSA, T. Association between craniomandibular disorders and occlusal interferences. J. prosthet. Dent., v.62, n.1, p.66-9, July 1989.

41. KIRVESKARI, P.; ALANEN, P.; JANSA, T. Association between craniomandibular disorders and occlusal interferences in children. $\mathbf{J}$. prosthet. Dent., v.67, n.6, p.692-6, May 1992.

42. KVINNSLAND, S.; KVINNSLAND, I.; KRISTIANSEN, A.B. Effect of experimental traumatic occlusion on blood flow in the temporomandibular joint of the rat. Acta odont. Scand., v.51, n.5, p.293-8, Oct. 1993.

43. LAMBRECHTS, P.; BRAEM, M.; VANHERLE, G. Evaluation of clinical performance for posterior composite resisns and dentine adhesives. Oper. Dent., v. 12, n.2, p.53-78, Spring. 1987.

44. LEE, W.C.; EAKLE, W.S. Possible role of tensile stress in the etiology of cervical erosive lesions of teeth. J. prosthet. Dent., v. 52, n.3, p.374-80, Sept. 1984.

45. LYONS, K. Aetiology of abfraction lesions. New Zealand dent. J., v. 497, n.4, p.93-8, Sept.. 2001.

46. MAGNUSSON, T.; ENBOM, L. Signs and symptoms of mandibular dysfunction after introduction of experimental balancing-side interferences. Acta odont. Scand., v.42, n.3, p.129-35, June 1984. 
47. MC GLYNN, F.D. et al. The effect of experimental stress and experimental occlusal interference on masseteric EMG activity. $\mathbf{J}$ craniomandibular disord. facial oral Pain., v. 3, n.2, p. 87-92, Spring. 1989.

48. MCNAMARA Jr, J.; SELIGMAN, D.A; OKESON, J.P. Occlusion orthodontic treatment, and temporomandibular disorders: a review. J. orofac. Pain., v.9, n. 1, p. 73-99, Winter. 1995.

49. MCNEIL, C. et al. Craniomandibular (TMJ) disorders - the state of the art. J. prosthet. Dent., 1980; :434-7.

50. MOHLIN,B.; INGERVALL,B.; THILANDER,B. Relation between malocclusion and mandibular dysfunction in swedish men. Europ. J. Orthodont., v.2, n.4, p.229-38, 1980.

51. NISHIDE, N.; et al. Histological study of rat masseter muscle following experimental occlusal alteration. J. oral Rehab., v.28, n. 3, p. 294-8, Mar. 2001.

52. OKESON JP. Management of temporomandibular disorders and occlusion. St Louis, Mosby, 1989.

53. PIOTROWSKI, B. T.; GILLETTE, W. B.; HANCOCK, E. B. Examining the prevalence and characteristics of abfractionlike cervical lesions in a population of U.S. veterans. J. Amer. dent. Ass., v. 132, n.12, p.1694-701, Dec. 2001.

54. POLSON, A.M.; MEITNER, S.W.; ZANDER, H.A. Trauma and progression of marginal periodontitis in squirrel monkeys. III. adaptation of interproximal 
alveolar bone to repetitive injury. J. Periodontol., v.11, n.5, p.279-89, Sept. 1976.

55. POLSON, A.M.; MEITNER, S.W.; ZANDER, H.A. Trauma and progression of marginal periodontitis in squirrel monkeys. IV. reversibility of bone loss due to trauma alone and trauma superimposed upon periodontitis. J. Periodontol., v.11, n.5, p.290-9, Sept. 1976.

56. PULLINGER, A.D.; SELIGMAN, D.A. Quantification and validation of predictive values of occlusal variables in temporomandibular disorders using a multifactorialanalysis. J. prosthet. Dent., v.83, n.1, p.66- 75, Jan. 2000.

57. PULLINGER, A.D.; SELIGMAN, D.A.; SOLBERG, W.K. Temporomandibular disorders. Part I: functional status, dentomorphologic features, and sex differences in a nonpatients population. J. prosthet. Dent., v.59, n.2, p.22835, Feb. 1988.

58. PULLINGER, A.D.; SELIGMAN, D.A.; SOLBERG, W.K. Temporomandibular disorders. part II: occlusal factors associated with temporomandibular joint tenderness and dysfunction. J. prosthet. Dent., v.59, n.3, p.363-7, Mar. 1988.

59. RAMJORD, J.P.; ASH, M.M. Occlusion. 3.ed. Philadelphia, W.B. Saunders Co, 1983.

60. REES, J.S. The role of cuspal flexure in the development of abfraction lesions: a finite element study. Eur. J. oral Sci., v. 106, n.6, p.1028-32, Dec. 1998. 
61. RICHARDIN, A. et al. Influence of stress and occlusal interference on the EMG activity of some masticatory muscles during a single mastication cycle. $\mathbf{J}$. oral Rehab., v.22, n. 10, p. 775-80, Oct. 1995.

62.RIISE, C.; SHEIKHOLESLAM, A. The influence of experimental interfering occlusal contacts on postural activity of the anterior temporal and masseter muscles in young adults J. oral Rehab., v.9, n. 5, p. 419-25, Sep. 1982.

63.RIISE, C.; SHEIKHOLESLAM, A. Influence of experimental interfering occlusal contacts on activity of the anterior temporal and masseter muscles during mastication. J. oral Rehab., v.11, n. 4, p. 325-33, July 1984.

64.RUBEN, M.P.; MAFLA, E. Effects of traumatic occlusion on the temporomandibular joint of Rhesus monkeys. J. Periodontol., v.42, n.2, p.79-87, Feb. 1971.

65. RUNGE, M.E. et al. The relationship between temporomandibular joint sounds and malocclusion. Amer. J. Orthod. Dentofac. Orthop., v.96, n.1, p. 3642,Jan. 1989.

66. SCHAERER, P.; STALLARD, R.E.; ZANDER, H.A. Occlusal interferences and mastication: an electromyographic study. J. prosthet. Dent. v.17, n.5, p.521-31, May 1995.

67. SELIGMAN,D.A.; PULLINGER,A.D. The role of intercuspal oclusal relationship in temporomandibular disorders: a review. J craniomandibular disord. facial oral Pain., v. 5, n.2, p. 96-106, Fall 1991. 
68. SELIGMAN,D.A.; PULLINGER,A.G.; SOLBERG,W.K. Temporomandibular disorders. pat III: occlusal and articular factors associated with muscle tenderness. J. prosthet. Dent., v.59, n.4, p. 483-9, apr. 1988.

69. SHEIKHOLESLAM, A.; RIISE, C. The influence of experimental interfering occlusal contacts on the activity of the anterior temporal and masseter muscles during submaximal and maximal bite in the intercuspal position. J. oral Rehab., v.10, n. 3, p. 207-14, May 1983.

70. SOLBERG,W.K.; WOO,M.W.; HOUSTON, J.B. Prevalence of mandibular dysfunction in young adults. J. Amer. dent. Ass., v.98, n.1, p.25-34, Jan. 1979.

71. STOHLER, C.S. Aparelhos (Placas) interoclusais - eles oferecem vantagem biológica? In: MCNEIL, C. Ciência e pratica da oclusão. São Paulo, Quintessence, 2000. p.381-93.

72.SVANBERG, G.; LINDHE, J. Vascular reactions in the periodontal ligament incident to trauma from occlusion. J. clin. Periodontol., v.1, n.1, p.58-69, Jan. 1974.

73. WATANABE, E.K. et al. The relationship between signs and symptomas of temporomandibular disorders and bilateral occlusal contact patterns during lateral excursions. J. oral Rehab., v.25, n. 6, p. 409-15, Jun. 1998.

74. WENTZ, F.M.; JARABAK, J.; ORBAN, B. Experimental occlusal trauma imitating cuspal interferences. J. Periodontol., v.29, n.6, p.117-27, June 1958. 
75. WESTLING, L. Occlusal interferences in retruded contact position and temporomandibular joint sounds. J. oral Rehab., v.22, n. 8, p. 601-6, Aug. 1995.

76. XHONGA, F.A. Bruxism and effect on the teeth. J. oral Rehab., v. 4, n.1, p.6576, Jan . 1977. 
Abstract 


\section{Abstract}

In the present days, occlusion has not been considered important etiologic factor for the development of temporomandibular disorders(TMD) symptoms. However, some features seems to be specially important as contributory factor. Slides from retruded position(RP) to intercuspal position(IP) greater than $4 \mathrm{~mm}$ are judged as one of those itens.

The aim of this study was to evaluated the cause/ effect relationship those interfernces and different clinical signs, including TMD.

Sample was constructed by 43 patients with the great interference, recorded in the anterior region in both positions. Patients with 5 or more posterior missing teeth or perform by orthodontic therapy were excluded. There was no relationship or any association between the interferences and clinical signs, including TMD. Author concluded that slides from RP to IP can not be considered a potential risk factor for TMD.

Key-Words: occlusal interference, temporomandibular disorder, occlusal trauma, occlusion, contact retruded position. 
Anexos 
Anexo 1: Ficha clínica.

\section{UNIVERSIDADE DE SÃO PAULO}

Faculdade de Odontologia de Bauru

Nome: Data nascimento:

Endereço:

Bairro: Cidade: Estado: CEP:

Fone: Idade: Sexo:

\section{EXAME CLÍNICO:}

1- ALTURA DA INTERFERÊNCIA: $\mathrm{mm}$

2- DOR MUSCULAR

Sim Não

3- DOR ARTICULAR

Sim Não

4- PRESENÇA DE RUIDOS

Sim Não 
5- EVIDÊNCIAS DE INTERFERÊNCIA OCLUSAL

Sim Não

6- FACETA

Sim Não

7- MOBILIDADE DENTÁRIA

Sim Não

8- RECESSÃO GENGIVAL

Sim Não

9- ABFRAÇÃO

Sim Não

9- DOR DENTÁRIA LOCALIZADA

Sim Não

10- AUSÊNCIA DE DENTES POSTERIORES

\begin{tabular}{|l|l|l|l|l|l|l|l|l|l|l|l|l|l|l|l|}
\hline 18 & 17 & 16 & 15 & 14 & 13 & 12 & 11 & 21 & 22 & 23 & 24 & 25 & 26 & 27 & 28 \\
\hline 48 & 47 & 46 & 45 & 44 & 42 & 42 & 41 & 31 & 32 & 33 & 34 & 35 & 36 & 37 & 38 \\
\hline
\end{tabular}


Anexo 2: Carta de informação ao paciente.

Título do trabalho: "Avaliação da magnitude das interferências oclusais e sua relação com os sinais clínicos de trauma oclusal e sinais e sintomas de Desordens Têmporo-mandibulares".

Autores: Tatiany de Mendonça Neto e Prof. Dr. Carlos dos Reis Pereira de Araujo.

Neste estudo serão realizados exames corriqueiros em clínica odontológica e necessários para avaliar a presença de dor ou a presença de sinais que possam provocar algum dano ao bem estar do paciente. Os materiais que serão utilizados encontram-se disponíveis no mercado e foram previamente estudados através de testes de comportamento físico e estudos prévios de biocompatibilidade, não demonstrando nenhum risco àintegridade do ser humano.

O paciente será examinado externamente através de palpação com as mãos, e a avaliação intrabucal será realizada com a ajuda de um aparelho pequeno de resina que será colocado nos dentes anteriores por quinze minutos. Com a ajuda deste aparelho o paciente morderá na posição correta para analisar os sinais de algum dano æ̀ articula ções, músculos e dentes.

Para realizar esta avaliação será necessária apenas uma consulta, e o paciente estará liberado para continuar o tratamento na clínica de origem.

Bauru, de de 2002.

Assinatura do Paciente

Documento apresentado: N. ${ }^{\circ}$ 
Anexo 3: Tabela 15.

TABELA 15: Dados individuais referentes àmagnitude da interferência oclusal, idade, sexo, dor muscular, dor articular, presença de ruídos articulares, evidências de interferência oclusal, facetas, mobilidade dentária, recessão gengival, abfração e dor dentária localizada.

\begin{tabular}{|c|c|c|c|c|c|c|c|c|c|c|c|c|}
\hline $\mathbf{A M}$ & ID & $\mathbf{S X}$ & $\mathbf{A I}$ & DM & $\mathbf{D A}$ & PR & EIO & FA & MD & RG & $\mathbf{A B}$ & DDL \\
\hline 01 & 36 & $\mathrm{~F}$ & 0 & $S$ & $S$ & $S$ & $\mathrm{~N}$ & $\mathrm{~S}$ & $\mathrm{~N}$ & $S$ & $S$ & $\mathrm{~N}$ \\
\hline 02 & 45 & $\mathrm{~F}$ & 1 & S & S & S & S & $S$ & $\mathrm{~N}$ & S & $\mathrm{N}$ & $\mathrm{N}$ \\
\hline 03 & 30 & $\mathrm{M}$ & 0 & $\mathrm{~N}$ & $\mathrm{~N}$ & $\mathrm{~S}$ & $S$ & $\mathrm{~S}$ & $\mathrm{~N}$ & $S$ & $\mathrm{~N}$ & $\mathrm{~N}$ \\
\hline 04 & 22 & $\mathrm{~F}$ & 2 & $S$ & $\mathrm{~N}$ & $\mathrm{~S}$ & $S$ & $\mathrm{~N}$ & $\mathrm{~N}$ & $\mathrm{~N}$ & $\mathrm{~N}$ & $\mathrm{~N}$ \\
\hline 05 & 30 & $\mathrm{~F}$ & 1 & $\mathrm{~N}$ & $S$ & S & S & $S$ & $\mathrm{~N}$ & S & $S$ & $\mathrm{~N}$ \\
\hline 06 & 29 & $\mathrm{~F}$ & 2 & $S$ & $\mathrm{~N}$ & $\mathrm{~N}$ & $S$ & $\mathrm{~S}$ & $\mathrm{~N}$ & $\mathrm{~N}$ & $\mathrm{~N}$ & $\mathrm{~N}$ \\
\hline 07 & 22 & $\mathrm{~F}$ & 1 & $S$ & $S$ & $\mathrm{~S}$ & S & S & $S$ & $\mathrm{~N}$ & $\mathrm{~N}$ & $\mathrm{~N}$ \\
\hline 08 & 30 & $\mathrm{M}$ & 1,5 & $\mathrm{~N}$ & $\mathrm{~N}$ & $\mathrm{~N}$ & $S$ & $\mathrm{~S}$ & S & $S$ & $S$ & $\mathrm{~N}$ \\
\hline 09 & 28 & $\mathrm{~F}$ & 1 & $S$ & $\mathrm{~N}$ & $\mathrm{~N}$ & $S$ & $\mathrm{~S}$ & $S$ & $\mathrm{~N}$ & $\mathrm{~S}$ & $\mathrm{~N}$ \\
\hline 10 & 37 & $\mathrm{~F}$ & 1,5 & $\mathrm{~N}$ & $S$ & $\mathrm{~N}$ & S & $\mathrm{S}$ & S & $S$ & $S$ & $\mathrm{~N}$ \\
\hline 11 & 39 & $\mathrm{~F}$ & 3 & S & $S$ & $\mathrm{~N}$ & S & S & $\mathrm{N}$ & $\mathrm{N}$ & $\mathrm{N}$ & $\mathrm{N}$ \\
\hline 12 & 50 & $\mathrm{~F}$ & 2 & S & $\mathrm{N}$ & $\mathrm{S}$ & S & $\mathrm{S}$ & $\mathrm{N}$ & $\mathrm{N}$ & $\mathrm{N}$ & $S$ \\
\hline 13 & 62 & $\mathrm{~F}$ & 0,5 & $\mathrm{~N}$ & $S$ & $\mathrm{~S}$ & $S$ & $\mathrm{~N}$ & $S$ & $S$ & $S$ & $\mathrm{~N}$ \\
\hline 14 & 39 & $\mathrm{M}$ & 1 & S & $S$ & S & S & $S$ & $\mathrm{~N}$ & S & $S$ & $S$ \\
\hline 15 & 43 & $\mathrm{~F}$ & 0 & $S$ & S & $\mathrm{S}$ & $\mathrm{N}$ & $\mathrm{N}$ & $\mathrm{N}$ & $\mathrm{N}$ & $\mathrm{N}$ & $\mathrm{N}$ \\
\hline 16 & 25 & $\mathrm{~F}$ & 2 & $\mathrm{~S}$ & $S$ & $\mathrm{~S}$ & $\mathrm{~N}$ & $\mathrm{~N}$ & $\mathrm{~N}$ & $\mathrm{~N}$ & $\mathrm{~N}$ & $\mathrm{~N}$ \\
\hline 17 & 20 & $\mathrm{~F}$ & 2 & $S$ & $S$ & $\mathrm{~S}$ & $S$ & $\mathrm{~S}$ & $S$ & $\mathrm{~N}$ & $S$ & $\mathrm{~N}$ \\
\hline 18 & 16 & $\mathrm{~F}$ & 0,5 & $S$ & $S$ & $\mathrm{~S}$ & $S$ & $\mathrm{~S}$ & $\mathrm{~N}$ & $\mathrm{~N}$ & $\mathrm{~S}$ & $\mathrm{~N}$ \\
\hline 19 & 15 & $\mathrm{~F}$ & 0 & S & $S$ & $\mathrm{~S}$ & $\mathrm{~N}$ & $\mathrm{~N}$ & $\mathrm{~N}$ & $\mathrm{~N}$ & $\mathrm{~N}$ & $\mathrm{~N}$ \\
\hline 20 & 22 & $\mathrm{~F}$ & 0,5 & $S$ & $S$ & $\mathrm{~N}$ & $\mathrm{~N}$ & $\mathrm{~N}$ & $\mathrm{~N}$ & $\mathrm{~N}$ & $\mathrm{~N}$ & $\mathrm{~N}$ \\
\hline 21 & 20 & $\mathrm{~F}$ & 4 & $S$ & $S$ & $\mathrm{~S}$ & $S$ & $\mathrm{~S}$ & $\mathrm{~N}$ & $\mathrm{~N}$ & $\mathrm{~N}$ & $\mathrm{~S}$ \\
\hline 22 & 18 & $\mathrm{M}$ & 1,5 & S & $\mathrm{N}$ & $\mathrm{N}$ & S & $\mathrm{S}$ & $\mathrm{N}$ & $\mathrm{N}$ & $\mathrm{N}$ & $\mathrm{N}$ \\
\hline
\end{tabular}

ID - idade, SX - sexo, MIO - magnitude da interferência oclusal, DM - dor muscular, DA - dor articular, RA presença de ruídos articulares, EIO - evidências de interferência oclusal, FA- facetas, MD - mobilidade dentária, $\mathrm{RG}$ - recessão gengival, $A B$ - abfração e DDL - dor dentária localizada. 
TABELA 15: Dados individuais referentes àmagnitude da interferência oclusal, idade, sexo, dor muscular, dor articular, presença de ruídos articulares, evidências de interferência oclusal, facetas, mobilidade dentária, recessão gengival, abfração e dor dentária localizada.

\begin{tabular}{|c|c|c|c|c|c|c|c|c|c|c|c|c|}
\hline $\mathbf{A M}$ & ID & $\mathbf{S X}$ & $\mathbf{A I}$ & DM & $\mathbf{D A}$ & PR & EIO & $\mathbf{F A}$ & MD & RG & $\mathbf{A B}$ & DDL \\
\hline 23 & 16 & $\mathrm{~F}$ & 1,5 & $S$ & $S$ & $\mathrm{~S}$ & $\mathrm{~N}$ & $\mathrm{~N}$ & $\mathrm{~N}$ & $\mathrm{~N}$ & $\mathrm{~N}$ & $\mathrm{~N}$ \\
\hline 24 & 46 & $\mathrm{~F}$ & 2 & $S$ & $\mathrm{~N}$ & $\mathrm{~N}$ & $\mathrm{~N}$ & $\mathrm{~N}$ & $\mathrm{~N}$ & $\mathrm{~N}$ & $\mathrm{~N}$ & $\mathrm{~N}$ \\
\hline 25 & 21 & $\mathrm{M}$ & 0 & $S$ & $S$ & $\mathrm{~S}$ & $S$ & $S$ & $\mathrm{~N}$ & $\mathrm{~N}$ & $\mathrm{~N}$ & $\mathrm{~N}$ \\
\hline 26 & 53 & $\mathrm{~F}$ & 0 & $S$ & $S$ & $\mathrm{~S}$ & $\mathrm{~N}$ & $\mathrm{~N}$ & $\mathrm{~N}$ & $\mathrm{~N}$ & $\mathrm{~N}$ & $\mathrm{~N}$ \\
\hline 27 & 35 & $\mathrm{~F}$ & 5 & $\mathrm{~N}$ & $\mathrm{~N}$ & $\mathrm{~N}$ & $S$ & $\mathrm{~S}$ & $S$ & $\mathrm{~N}$ & $\mathrm{~S}$ & $\mathrm{~N}$ \\
\hline 28 & 50 & $\mathrm{~F}$ & 5 & $\mathrm{~N}$ & $\mathrm{~N}$ & $\mathrm{~S}$ & $S$ & $\mathrm{~S}$ & $S$ & $\mathrm{~N}$ & $\mathrm{~N}$ & $\mathrm{~N}$ \\
\hline 29 & 37 & $\mathrm{~F}$ & 6 & $\mathrm{~N}$ & $\mathrm{~N}$ & $\mathrm{~N}$ & $S$ & $\mathrm{~S}$ & $\mathrm{~N}$ & $S$ & $\mathrm{~S}$ & $S$ \\
\hline 30 & 57 & $\mathrm{M}$ & 3 & $\mathrm{~N}$ & $\mathrm{~N}$ & $\mathrm{~N}$ & $S$ & $\mathrm{~S}$ & $\mathrm{~N}$ & $S$ & $\mathrm{~S}$ & $S$ \\
\hline 31 & 48 & $\mathrm{M}$ & 3 & $\mathrm{~N}$ & $\mathrm{~N}$ & $\mathrm{~N}$ & $S$ & $\mathrm{~S}$ & $\mathrm{~N}$ & $S$ & $\mathrm{~S}$ & $\mathrm{~N}$ \\
\hline 32 & 46 & $\mathrm{M}$ & 4 & $\mathrm{~N}$ & $\mathrm{~N}$ & $\mathrm{~N}$ & $S$ & $\mathrm{~S}$ & $S$ & $S$ & $\mathrm{~S}$ & $\mathrm{~N}$ \\
\hline 33 & 58 & $\mathrm{~F}$ & 3 & $S$ & $S$ & $\mathrm{~N}$ & $S$ & $\mathrm{~S}$ & $S$ & $S$ & $\mathrm{~S}$ & $\mathrm{~S}$ \\
\hline 34 & 35 & $\mathrm{M}$ & 5 & $\mathrm{~N}$ & $\mathrm{~N}$ & $\mathrm{~N}$ & $S$ & $\mathrm{~N}$ & $\mathrm{~N}$ & $S$ & $\mathrm{~S}$ & $\mathrm{~N}$ \\
\hline 35 & 46 & $\mathrm{~F}$ & 3 & $\mathrm{~N}$ & $\mathrm{~N}$ & $\mathrm{~N}$ & $\mathrm{~S}$ & $\mathrm{~S}$ & $S$ & $\mathrm{~N}$ & $\mathrm{~S}$ & $\mathrm{~N}$ \\
\hline 36 & 42 & $\mathrm{~F}$ & 2 & $S$ & $S$ & $S$ & $\mathrm{~N}$ & $\mathrm{~N}$ & $\mathrm{~N}$ & $\mathrm{~N}$ & $\mathrm{~N}$ & $\mathrm{~N}$ \\
\hline 37 & 46 & $\mathrm{~F}$ & 3 & $S$ & $S$ & $\mathrm{~S}$ & $S$ & $\mathrm{~N}$ & $\mathrm{~N}$ & $\mathrm{~N}$ & $\mathrm{~N}$ & $\mathrm{~N}$ \\
\hline 38 & 45 & $\mathrm{M}$ & 5 & $S$ & $\mathrm{~N}$ & $\mathrm{~N}$ & $S$ & $\mathrm{~S}$ & $S$ & $S$ & $\mathrm{~S}$ & $\mathrm{~N}$ \\
\hline 39 & 36 & $\mathrm{~F}$ & 3 & $S$ & $\mathrm{~N}$ & $\mathrm{~N}$ & $\mathrm{~S}$ & $\mathrm{~S}$ & $S$ & $\mathrm{~N}$ & $\mathrm{~N}$ & $\mathrm{~N}$ \\
\hline 40 & 54 & $\mathrm{~F}$ & 5 & $S$ & $S$ & $\mathrm{~N}$ & $S$ & $\mathrm{~S}$ & $\mathrm{~N}$ & $\mathrm{~S}$ & $\mathrm{~S}$ & $\mathrm{~N}$ \\
\hline 41 & 36 & $\mathrm{~F}$ & 3 & $S$ & $\mathrm{~N}$ & $\mathrm{~S}$ & $S$ & $\mathrm{~S}$ & $S$ & $S$ & $\mathrm{~N}$ & $\mathrm{~S}$ \\
\hline 42 & 47 & $\mathrm{M}$ & 6 & $\mathrm{~N}$ & $\mathrm{~N}$ & $\mathrm{~N}$ & $S$ & $\mathrm{~S}$ & $\mathrm{~N}$ & $S$ & $\mathrm{~N}$ & $\mathrm{~N}$ \\
\hline 43 & 32 & $\mathrm{M}$ & 3 & $S$ & $\mathrm{~N}$ & $\mathrm{~S}$ & $\mathrm{~N}$ & $\mathrm{~S}$ & $\mathrm{~N}$ & $\mathrm{~N}$ & $\mathrm{~N}$ & $\mathrm{~N}$ \\
\hline
\end{tabular}

ID - idade, SX - sexo, MIO - magnitude da interferência oclusal, DM - dor muscular, DA - dor articular, RA presença de ruídos articulares, EIO - evidências de interferência oclusal, FA- facetas, MD - mobilidade dentária, $R G$ - recessão gengival, $A B$ - abfração e DDL - dor dentária localizada. 